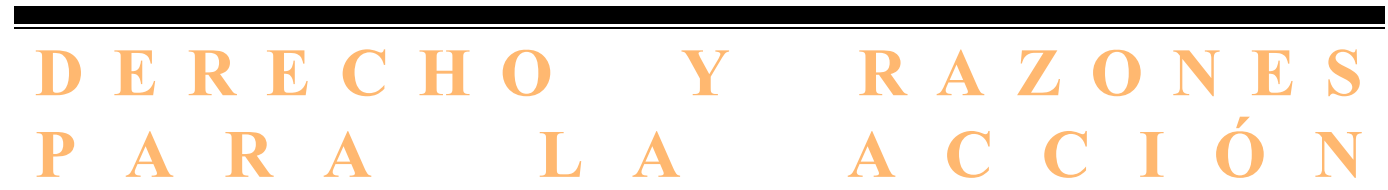




\section{RAZONES Y REGLAS: SOBRE EL CONCEPTO DE "RAZÓN EXCLUYENTE" DE JOSEPH RAZ}

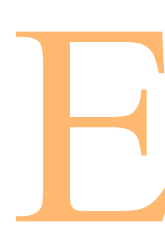

$\mathrm{n}$ los quince años que median entre las fechas de publicación de la primera y la segunda de las ediciones de Practical Reason and Norms ${ }^{1}$, Joseph Raz ha ido desarrollando, paso a paso, un vasto programa teórico cuyo objetivo central consiste en fundamentar una teoría del derecho dentro del marco de una ambiciosa teoría general de las razones para la acción. Bien puede decirse que el resultado de ese empeño cruza y diluye las fronteras convencionales entre teoría jurídica, filosofía política y teoría general del discurso práctico: la caracterización raziana del derecho no puede entenderse si no es a partir de su análisis de la idea de autoridad legítima; y ésta, a su vez, no es inteligible a menos que se tenga presente el peculiar aparato conceptual con el que Raz intenta reconstruir la estructura de los razonamientos prácticos, en el que la pieza más novedosa y al mismo tiempo más importante resulta ser la noción de «razón excluyente».

Del papel central de este último concepto dentro del proyecto raziano seguramente da idea el hecho de que la única novedad de la segunda edición de $P R N$ sea precisamente un apéndice consagrado por entero a perfilarlo y defenderlo frente a posibles críticas y -lo que a Raz le parece que son- malentendidos. Pero, en cualquier caso, el interés de esta idea trasciende a mi juicio el marco de la obra de su autor. No me parece aventurado afirmar

${ }^{1}$ Vid. las referencias bibliográficas recogidas al final de este trabajo. La segunda edición de Practical Reason and Norms [en adelante, $P R N$ ] reproduce el texto de la primera con la única novedad de la inclusión de un apéndice, «Rethinking Exclusionary Reasons», pp. 178-199 (y de las notas correspondientes al mismo: pp. 211-217). Hasta el comienzo de dicho apéndice, la 2. ${ }^{\mathrm{a}}$ ed. mantiene además la paginación de la primera. El texto común a ambas ediciones se cita en lo sucesivo como «PRN, 1975 / 1990»; el del nuevo apéndice, como «PRN, 1990». 
que con su concepto de «razón excluyente» Raz ha acertado a dar forma a una intuición que, de modo más o menos vago, estaba y está presente en la cultura filosófico-jurídica de la que es interlocutor. Y eso explicaría su rápida y entusiasta acogida por parte de algunos de sus más sobresalientes representantes, y entre todos ellos, desde luego, por el mismo Hart, que ve ahora en la idea central de una «razón jurídica autoritativa»-de la que expresamente reconoce que es tributaria del concepto de «razón excluyente» de Raz- la clave para la intelección del fenómeno jurídico. ${ }^{2}$

El propósito de este trabajo no es otro que el de examinar críticamente la noción de razón excluyente ${ }^{3}$. Dividiré mi exposición en dos partes: en la primera, trataré de sintetizar las ideas fundamentales de Raz y de dar cuenta del modo en que se engarzan su análisis de la autoridad, su concepción del derecho y su análisis general de la estructura de los razonamientos prácticos, así como de la posición central que en todo ello desempeña la noción de razón excluyente. En la segunda, intentaré demostrar que Raz hace un uso ambiguo de dicha noción; que un análisis satisfactorio de la estructura de los razonamientos prácticos, por complejos que éstos sean, puede prescindir de ella; y que la pretensión de que hay razones excluyentes válidas puede tener como resultado la irracionalidad desde el punto de vista práctico.

\section{El proyecto de $\operatorname{Raz}$}

\section{1. Una concepción de la autoridad legítima}

Normalmente suele darse por sentado que aceptar la autoridad de otro como legítima implica reconocer su derecho a mandarme

${ }^{2}$ Cfr. Hart, 1982, cap. X, especialmente pp. 243-244 y 253 ss, Sobre la influencia de las tesis de Raz en la evolución del pensamiento hartiano, vid. Farrell, 1986. Véase además la acogida y el uso que del concepto de razón excluyente hacen Hacker, 1973, pp. 165-166; Finnis, 1980, pp. 234, 308 y 319; Jori, 1980, pp. 5-7 que acude al análisis de Raz en $P R N$ para construir su análisis de las normas como instrumentos para realizar elecciones prácticas «al por mayor», y no caso por caso; Nardin, 1983, p. 11; o Atiyah y Summers, 1987, pp. 2 y 7-8, que reconocen el parentesco entre su noción de «razón formal» y la raziana de «razón excluyente», a pesar de apreciar entre ambas algunas diferencias.

${ }^{3}$ Desde la publicación de la $1 .^{\mathrm{a}}$ ed. de $P R N$ no han faltado quienes, de manera más o menos extensa y articulada, han criticado expresamente este concepto raziano: cfr. Clarke, 1977; Flathman, 1980, pp. 111-113 y 258-259; Gans, 1981, cap. IV; Moore, 1989; y Perry, 1989. Por mi parte, he analizado el concepto de razón excluyente con mayor extensión de la que aquí resulta posible en Bayón, 1991, especialmente apartado 8.2. 
y mi deber de obedecerle, entendiendo que dicho reconocimiento supondría no sólo la admisión de que debo hacer lo que la autoridad ordene a condición de que coincida con lo que de todos modos pienso que se ha de hacer, sino la aceptación de que debo hacer lo que ordene aunque no exista esa coincidencia, aunque con arreglo a mi propio juicio entienda que he de hacer algo diferente. Correlativamente, pretender que se tiene autoridad legítima sobre otro equivaldría a sostener que hay razones para que éste reconozca el deber de hacer lo que le ordenemos en los términos descritos.

Puede que este análisis de la idea de autoridad sea erróneo. Pero lo que no cabe ignorar es que quien lo dé por bueno tiene ante sí un arduo problema, -al que Raz no ha dudado en referirse como «la paradoja de la autoridad» $»^{4}:$ si la aceptación de la autoridad de otro implica deponer y postergar el propio juicio acerca de lo que se ha de hacer, ¿cómo es posible que un sujeto racional acepte alguna «autoridad legítima» sobre sí? ¿cómo es posible que haya alguna autoridad que verdaderamente sea legítima (y no meramente autoridades que irracionalmente son tenidas por legítimas)? La suspensión o postergación del juicio propio tiene que ser racionalmente justificada si se quiere demostrar la mera posibilidad conceptual de que exista alguna autoridad auténticamente legítima: pero la dificultad estriba en aclarar de qué modo sería posible semejante justificación, dado que, al menos en apariencia, la racionalidad práctica consistiría por definición -desde el punto de vista de cada sujeto- en hacer justamente aquello que se entiende que hay razones concluyentes para hacer.

Esta paradoja de la autoridad puede ser examinada igualmente desde otra perspectiva. Aparentemente, si las prescripciones de la autoridad coinciden con lo que moralmente debe hacerse, ciertamente habrá razones para actuar del modo prescrito: pero que la autoridad lo haya ordenado no será una de esas razones (habría exactamente las mismas razones para hacerlo aunque dichas prescripciones no se hubieran dictado o fueran revocadas). Y si no coinciden, dado que siempre ha de hacerse lo moralmente correcto, habrá razones para transgredir aquellas prescripciones. Así que, cualquiera que sea el caso, las prescripciones de la autoridad siempre serían irrelevantes desde el punto de vista moral, esto es, del ejercicio de la autoridad no podría derivarse diferencia alguna respecto a lo que moralmente deben hacer los sometidos a ella ${ }^{5}$.

${ }^{4}$ Cfr. Raz, 1982, pp. 17-18.

${ }^{5}$ Así plantea el problema Nino, refiriéndose a él como paradoja de la «irrelevancia moral del gobierno»: cfr. Nino, 1989a, p. 370; 1989b, p. 118. Nino 
Me parece que la mayor virtud de la concepción raziana de la autoridad legítima radica en haber tomado en serio la fuerza de estas paradojas. O dicho de otro modo: en haber partido de la base de que ninguna concepción de la autoridad legítima puede considerarse satisfactoria a menos que consiga sortearlas con éxito. La vía a través de la cual intenta hacerlo él se asienta sobre esta idea matriz: que en ocasiones el intento de actuar según un cierto conjunto de razones resulta auto-frustrante, y que en esos casos lo que la racionalidad exige es el seguimiento de una estrategia indirecta, es decir, el abandono del intento de tomar la propia apreciación acerca de lo que exige aquel conjunto de razones como guía directa de la acción, teniendo sin embargo dicho abandono como resultado el mejor seguimiento de las mismas. Si fuese posible demostrar que, al menos en determinadas circunstancias, un individuo ajusta mejor su conducta al conjunto de razones para actuar que efectivamente tiene si, en vez de seguir su propia estimación acerca de qué es lo que aquellas razones exigirían en esa ocasión, hace lo que la autoridad le ordena que haga, habría quedado demostrado que suspender o postergar el propio juicio, lejos de suponer una abdicación de la racionalidad práctica, sería precisamente lo que haría un agente verdaderamente racional.

A juicio de Raz, hay efectivamente circunstancias en las que dicha demostración es posible. Y de ahí que denomine su propia tesis «concepción de la autoridad como servicio» [service conception of authority] ${ }^{6}$, puesto que la idea a defender consiste en que las autoridades son legítimas en la medida en que nos sirvan para actuar de conformidad con las razones que deben guiar nuestra acción de un modo mejor o más acertado que el que nos sería dado alcanzar sin ellas. Dicha concepción se resume en tres tesis, indisolublemente ligadas, en las que conviene detenerse brevemente.

Con arreglo a la primera de ellas - «tesis de la dependencia» ${ }^{7}-$, que es una tesis normativa acerca de cómo debe ejercerse la autoridad, si lo que justifica a ésta es el servir a quienes la aceptan para mejor actuar según las razones que efectivamente tienen, se sigue de ello que las directivas de la autoridad deben estar basadas

propone una original vía de salida para dicha paradoja, basada en lo que denomina el «valor epistemológico de la democracia» (vid. Nino, 1989a, pp. 387-400; 198b, pp. 129-133; y 1991), cuya plausibilidad no puede ser examinada dentro de los límites de este trabajo.

${ }^{6}$ Raz, 1986, p. 56.

${ }^{7}$ Raz, 1986, p. 47. 
en dichas razones, es decir, en las «razones subyacentes» ${ }^{8}$, en aquellas que, en ausencia de autoridades, el agente debería intentar seguir con arreglo a su propia apreciación de las mismas. Debe retenerse el dato de que entre las razones subyacentes que tiene el sometido a la autoridad se incluirían sus razones para modificar la situación o el contexto en el que actúa, de manera que en la situación resultante tenga razones para actuar que no tenía antes de llevarse a cabo dicha modificación (es lo que sucedería, según Raz, cuando el agente se encuentra inmerso en situaciones de interacción estratégica con la estructura del «dilema del prisionero» o de un problema de coordinación) ${ }^{9}$. Igualmente, la tesis de la dependencia autorizaría a la autoridad a basar sus directivas en razones «indirectamente subyacentes», es decir, en razones no estrictamente subyacentes cuyo seguimiento posibilita y maximiza sin embargo la conformidad global a las razones subyacentes: porque en ocasiones la mejor forma de lograr que la obediencia global a las directivas de la autoridad represente el seguimiento óptimo por parte de los sometidos a ella de las razones subyacentes pasa por la imposición de algunos deberes que en ausencia de autoridad éstos no tendrían, pero que son necesarios, por ejemplo, para la propia organización de la maquinaria a través de la cual se ejerce la autoridad ${ }^{10}$.

Con arreglo a la segunda - «tesis de la justificación normal» ${ }^{11}-$, para que una autoridad pueda ser considerada legítima o justificada no basta con que en su actuación se atenga a la tesis de la dependencia: además ha de poderse demostrar que un agente que simplemente obedezca sus directivas cumpliría mejor con las «razones subyacentes» que si, en absoluta ausencia de autoridad, tratara directamente de determinar por sí mismo qué es lo que éstas exigen y actuara de acuerdo con el resultado de dicha deliberación. La concurrencia de ambos requisitos es imprescindi-

${ }^{8}$ PRN, 1990, p. 193. En Raz, 1986, p. 47, no se hablaba de «razones subyacentes» [underlying reasons], sino de «razones dependientes» [dependent reasons], lo que me parece menos atinado, puesto que se trata de las razones de las que tiene que depender el contenido de las directivas de la autoridad. Pero aunque la nueva terminología sea más afortunada, el concepto manejado por Raz en uno y otro caso es exactamente el mismo.

${ }^{9}$ Raz, 1986, pp. 48-51.

${ }^{10}$ Raz, 1986, p. 52.

${ }^{11}$ Raz, 1986, p. 53. Raz habla de «tesis de la justificación normal» porque a su juicio lo que normalmente justifica a la autoridad es la satisfacción de la misma. Entiende no obstante que existirían además algunas vías complementarias para hacerla legítima o justificada que tendrían que ver con las ideas de «consentimiento»o «respeto», a las que no voy a referirme aquí. 
ble: si no se diera el segundo las directivas de la autoridad serían irrelevantes e inútiles desde el punto de vista práctico.

Por fin, la tercera tesis - «tesis del reemplazo» ${ }^{12}$ - «no sería sino un corolario o complemento natural de las otras dos, y se referiría al modo en que las directivas de la autoridad legítima o justificada habrían de incidir o ser tomadas en cuenta en el razonamiento práctico de su destinatario. La «concepción de la autoridad como servicio» pretende captar lo que, según Raz, es la verdadera razón de ser de la autoridad, que consistiría en el desplazamiento (avalado por la razón) de la toma de decisiones de una persona a otra. Si -por hipótesis- dicho desplazamiento es racional cuando un sujeto no es capaz de determinar por sí mismo qué es lo que exige en cada caso el conjunto de razones subyacentes con el mismo acierto con el que consigue hacerlo la autoridad legítima, se sigue de ello que las directivas de ésta no habrán de ser consideradas por aquél como una razón más que se añade a las razones subyacentes preexistentes, sino justamente como una que las desplaza y ocupa su lugar, esto es, que las reemplaza en el razonamiento práctico del destinatario; y ello simplemente porque, satisfaciendo la autoridad la tesis de la justificación normal, el sujeto cumpliría mejor con lo que las razones subyacentes exigen si, en vez de guiarse por su propia apreciación al respecto, se limita a hacer lo que la autoridad justificada ordena. De hecho, dado que las directivas de una autoridad legítima habrían de reflejar el balance de todas las razones subyacentes relevantes para el caso, considerarlas como una nueva razón que se añade a las razones subyacentes preexistentes supondría contar dos veces las mismas razones.

Por supuesto, toda esta elegante construcción formal pende de la posibilidad de demostrar, mediante argumentos sustantivos, que efectivamente -como supone Raz- hay circunstancias en las que un agente que simplemente obedezca las directivas de la autoridad cumpliría mejor con las razones subyacentes que si tratara directamente de determinar por sí mismo qué es lo que éstas exigen. De la plausibilidad de esos argumentos sustantivos me ocuparé más adelante. Pero antes convendría insistir en dos ideas que se derivan del análisis expuesto.

${ }^{12}$ «Raz, 1986, p. 46. «Reemplazo» es una traducción no completamente fiel del término «pre-emption», que, tomado del vocabulario jurídico y del de las reglas de ciertos juegos, expresaría aproximadamente la idea de adelantarse a otro a la hora de hacer algo y ganar así cierto derecho de prioridad sobre él; o la de ocupar cierta posición impidiendo así que la ocupe otro o desplazándole de ella. No obstante, en el sentido en el que lo emplea Raz, creo que puede hacerse equivaler sin demasiada distorsión a las ideas de «sustitución» o «reemplazo». 
En primer lugar, de ser globalmente sostenible, la concepción raziana de la autoridad legítima conseguiría la reconciliación de la idea de suspensión o postergación del propio juicio - que en cualquier caso se considera consustancial a la aceptación de autoridades- con la racionalidad práctica. Como el propio Raz señala, dicha idea no expresaría ya «el inmenso poder de las autoridades», sino, muy al contrario, «lo limitado de su papel» ${ }^{13}$ : lejos de traer consigo cualquier connotación de «obediencia ciega» o radicalmente acrítica a las autoridades, lo que subrayaría, rectamente entendida, sería que la función de la autoridad debe contraerse a hacer posible el seguimiento óptimo por parte de los sometidos a ella de las razones subyacentes que éstos tienen previa e independientemente, dado que en determinadas condiciones se encuentra en una mejor posición para propiciar dicho fin (y, consecuentemente, que la aceptación de una autoridad como legítima sólo es racional en esas condiciones y con esos límites) $)^{14}$.

$\mathrm{Y}$, en segundo lugar, que la naturaleza misma de la autoridad legítima se nos escaparía irremisiblemente si permanecemos anclados en una visión empobrecida de la estructura de los razonamientos prácticos, dentro de la cual todo lo que tiene cabida es la simple comparación lineal entre razones para actuar situadas en un mismo plano y nada más que eso. Lo que el análisis de Raz trata de poner de manifiesto es que la complejidad estructural de determinados razonamientos prácticos va mucho más lejos, y exige dar entrada a ideas tales como las de estrategias indirectas para maximizar la conformidad con cierto conjunto de razones mediante el seguimiento directo de otras que en algún sentido desplazan y sustituyen a las primeras (y que consiguientemente no operarían en sentido estricto en el mismo plano que éstas, sino que vendrían a ser «razones para no actuar por dichas razones»). Va siendo hora, por tanto, de explorar con detenimiento el denso aparato conceptual a través del cual ha intentado Raz representar adecuadamente esos niveles potenciales de complejidad. Pero antes conviene aludir brevemente al modo en que Raz conecta su concepción de la autoridad con su análisis de la naturaleza del derecho (lo que demostraría, de paso, que las categorías que va a

${ }^{13}$ Raz, 1985, p. 300.

${ }^{14}$ Una concepción semejante de la autoridad legítima tiene entonces como consecuencia que no todos los individuos ni en todas las ocasiones tienen las mismas razones para postergar su propio juicio y hacer simplemente lo que la autoridad ordena; $y$, dado que las autoridades políticas existentes típicamente no suelen reconocer esa salvedad, que la autoridad que éstas reclaman para sí excede normalmente de la que habría que atribuirles a la luz de la tesis de la justificación normal (cfr. Raz, 1986, p. 80). 
sacar a la luz ese análisis formal de los razonamientos prácticos no sólo serían imprescindibles para la fundamentación de ciertas tesis de filosofía política -como las relativas al concepto de autoridad legítima-, sino también para la de una teoría del derecho).

\subsection{Autoridad y derecho}

La tesis de la justificación normal define qué autoridades son legítimas. Pero por supuesto es posible que alguien considere legítima a una autoridad que realmente no lo es; o que alguien pretenda o reclame para sí una autoridad sobre otro sin que concurran las circunstancias que la harían legítima. Todo lo que cabe decir en tales casos es que aquel reconocimiento y esta pretensión serían irracionales (aunque los sujetos implicados piensen erróneamente lo contrario). La diferencia entre una autoridad que es legítima y una que es considerada como tal (o se pretende tal) permite en cualquier caso introducir el concepto de autoridad efectiva o de facto, es decir, de una autoridad que puede ser o no verdaderamente legítima, pero que en cualquier caso se pretende legítima y que en términos generales consigue ver cumplidas sus directivas por parte de aquellos sobre los que pretende tener autoridad (ya sea porque éstos reconocen efectivamente aquella pretensión, ya porque actúen guiados meramente por consideraciones de tipo prudencial, basadas en la posibilidad de que otros que probablemente sí la reconocen y que cuentan con la fuerza suficiente usen ésta en su contra).

Si un sistema jurídico existe habrá de poseer autoridad de facto. Lo que es tanto como decir -siempre a juicio de Raz- que pretende autoridad legítima ${ }^{15}$. Esta idea es verdaderamente central dentro del proyecto raziano: por un lado, permitiría captar la naturaleza misma del derecho como sistema normativo institucionalizado; por otro, ofrecería la base necesaria para preferir una tesis determinada entre las varias manejadas por la teoría jurídica acerca de la cuestión de la identificación de una norma como parte del derecho.

a) Es obvio que un sistema normativo desprovisto de institu-

${ }^{15}$ Cfr. Raz, 1982, cap. II; 1984, p. 131. Raz opina, no obstante, que todo derecho reclama para sí más autoridad de la que podría conferirle la tesis de la justificación normal: y de ahí su opinión de que no existe una obligación moral, ni siquiera prima facie, de obedecer el derecho. 
ciones aplicadoras de sus normas difiere notablemente de los sistemas jurídicos nacionales modernos. Éstos son a su vez profundamente distintos de lo que Raz denomina «sistemas de absoluta discreción», es decir, sistemas de normas que meramente instituyen y regulan el funcionamiento de órganos llamados a resolver conflictos mediante la emisión de pronunciamientos a los que se considera revestidos de autoridad, pero que, en la medida en que consisten sólo en eso, no establecen ningún conjunto de normas especificadas de antemano como criterios que deberían guiar las decisiones de dichos órganos: de éstos se esperaría entonces, simplemente, que decidieran en cada caso sobre la base de lo que con arreglo a su propio criterio estimaran que era el balance de todas las razones en juego.

Lo característico entonces de los genuinos sistemas normativos institucionalizados -entre los cuales los más importantes serían los sistemas jurídicos- sería la presencia en ellos de lo que Raz denomina «órganos primarios» ${ }^{16}$, entendiendo por tales un cierto tipo especial de instituciones definido por la concurrencia de dos requisitos (o, si se quiere, por el funcionamiento combinado de dos tipos de relaciones de autoridad). En primer lugar, dichos órganos resuelven conflictos con arreglo a criterios especificados de antemano y provenientes de una o más fuentes a las que consideran dotadas de autoridad, lo que es tanto como decir que aceptan una justificación para no basar sus decisiones directamente en su propio criterio acerca de las razones de orden general aplicables al caso, sino en las directivas emitidas por cierta(s) autoridad(es) legisladora(s $)^{17}$. Y en segundo lugar, los órganos primarios son considerados a su vez como autoridades por otros órganos diferentes que imponen o ejecutan las decisiones de aqué-

${ }^{16}$ Cfr. PRN, 1975/1990, sec. 4.3; y Raz, 1982, cap. VI.

${ }^{17}$ Que alguien acepte que hay una justificación semejante por supuesto no implica que realmente la haya. Por otra parte, la actitud de los órganos primarios en relación con las directivas de las autoridades legisladoras plantea al menos dos problemas que aquí sólo voy a mencionar. El primero de ellos es el de si para la existencia del sistema normativo institucionalizado es condición necesaria que los órganos primarios -o quizá la mayoría de ellos-acepten realmente que existe aquella justificación o si, por el contrario, basta -la acepten o no-con que actúen como si la aceptaran; de esa cuestión me he ocupado en otro lugar, al que me permito remitir (vid. Bayón, 1991, apartado 9). El segundo, el de si dicha aceptación ha de tener o no necesariamente carácter moral: la respuesta negativa, como se sabe, ha sido tenazmente defendida por Hart, 1982, cap. X; para la defensa de la respuesta afirmativa -que me parece más convincente: cfr. Bayón, 1991, loc. cit.,-, vid. Raz, 1981, pp. 454-455 y 1984, pp. 130-131; Nino, 1984, 1985 caps. III y VII y 1986, pp. 49-53; y Ruiz Manero, 1990, pp. 172-179. 
llos, aceptando por su parte una justificación para limitarse a ejecutarlas postergando su propio juicio no sólo acerca de lo que exigen las razones directamente aplicables al caso, sino también acerca de lo que exigirían en cada ocasión las directivas emitidas por las autoridades legisladoras y que los órganos primarios toman como base de sus decisiones (lo que es tanto como decir que los órganos ejecutores aceptan una justificación para un doble reemplazo: de las razones de orden general aplicables al caso por las directivas de las autoridades legisladoras; y de su juicio acerca de lo que exigen éstas por la decisión al respecto de los órganos primarios) $)^{18}$.

Los pasos de la argumentación de Raz se concatenan por consiguiente de este modo: no es posible fijar los rasgos fundamentales de los sistemas jurídicos nacionales modernos si no se repara en su carácter de sistemas normativos institucionalizados ${ }^{19}$; la idea de un genuino sistema de esa clase exige la presencia del tipo peculiar de institución que son los órganos primarios; para comprender qué ha de entenderse por tal, hay que caer en la cuenta de una cierta estructuración compleja de relaciones de autoridad; y como la naturaleza misma de la noción de autoridad legítima se nos escaparía si no damos entrada a la idea de una estrategia indirecta para maximizar la conformidad con cierto conjunto de razones mediante el seguimiento directo de otras que en la deliberación práctica de un sujeto reemplazan a las primeras, este último concepto (i.e., el de una razón para no actuar por

${ }^{18}$ «Cfr. Raz, 1989,p. 1169. El analizar en estos términos la relación entre órganos ejecutores y órganos primarios seguramente proporciona la base para una caracterización metasistemática de éstos que evite un doble riesgo: por un lado, el círculo vicioso resultante de identificarlos con arreglo a las reglas secundarias del sistema y de identificar al mismo tiempo las reglas del sistema a partir de la práctica de reconocimiento de los propios órganos primarios; por otro, la tergiversación de la relación entre ambas clases de órganos que se produce al concebirla en términos meramente fácticos, de obediencia habitual, y no normativos. Sobre todo ello, véase el lúcido análisis de Ruiz Manero, 1990, pp. 124-134.

${ }^{19}$ «Para caracterizar satisfactoriamente los sistemas jurídicos haría falta además mostrar cuál sería su diferencia específica dentro del género más amplio de los sistemas normativos institucionalizados. Para Raz -cfr. PRN, 1975/1990, pp. 149-154-, dicha diferencia específica se encuentra en el tipo de relación entre el derecho y el resto de los sistemas de esa clase existentes en una sociedad (el derecho sería un sistema «comprensivo», que «pretende ser supremo» y «abierto»), y no tanto, como me parece a mí más decisivo, en el hecho de que sólo el derecho tenga tras de sí un aparato que (cuasi) monopoliza el uso de la fuerza (lo que, para Raz, sería un rasgo de todos los sistemas jurídicos conocidos, pero no una propiedad definitoria del concepto de «sistema jurídico»: cfr. $P R N, 1975 / 1990$, pp. 157-161). 
otras razones) resultaría ser imprescindible para la comprensión del fenómeno jurídico.

b) Pero además, según Raz, que el derecho pretenda autoridad legítima (y no sea concebible ni inteligible sin esa pretensión) proporcionaría la base para un argumento en favor de lo que cabe denominar la «tesis de las fuentes sociales», esto es, en favor de la tesis según la cual qué es y qué no es derecho es siempre una cuestión de hechos sociales complejos, y por tanto en contra de tesis rivales de ésta tales como la que Raz denomina «tesis de la coherencia» y que no es sino la idea dworkiniana de que el derecho consiste en normas identificables por sus fuentes sociales junto con el conjunto de principios no derivados de fuentes sociales que integran la mejor justificación moral global de aquellas normas.

El argumento es el siguiente. Que el derecho reclame para sí autoridad legítima no quiere decir que realmente la tenga siempre. Pero hay dos tipos de motivos por los que puede carecer de ella. Puede no tenerla, en primer lugar, porque falten las condiciones normativas requeridas, es decir, porque no concurran las circunstancias que hacen que quede satisfecha la tesis de la justificación normal. Pero también puede carecer de ella, en segundo lugar, porque no se den las condiciones no normativas que han de concurrir para que exista la capacidad misma de ser autoridad: dado el análisis raziano de la idea de autoridad legítima, que ya conocemos, nadie es materialmente capaz de funcionar como autoridad si no puede comunicar sus directivas que pretendidamente reflejan el balance de razones subyacentes y si dichas directivas y su contenido no pueden ser reconocidas e identificadas por sus destinatarios sin volver a plantear directamente la cuestión de qué es lo que resulta de ese balance. Dicho con otras palabras: el beneficio de contar con autoridades legítimas se pierde si no es posible establecer la existencia y contenido de sus directivas sin suscitar la cuestión misma que la autoridad legítima aspira a dar resuelta. Pero entonces se sigue de ello que la pretensión del derecho de contar con autoridad legítima tendría que ser absurda por principio si careciera de la capacidad material de funcionar como autoridad; y puesto que realmente carecería de dicha capacidad material si la «tesis de la coherencia» fuese la respuesta correcta a la pregunta «¿qué cuenta como derecho?, de todo ello resultaría que esta última tesis choca frontalmente con la pretensión central del derecho y que, por consiguiente, debe ser descartada en favor de su rival, la tesis de las fuentes sociales ${ }^{20}$.

${ }^{20}$ Vid. Raz, 1985, especialmente, pp. 300-305. El argumento ya aparecía esbozado -pero no plenamente desarrollado- en Raz, 1982, p. 72. 
En suma, tanto el análisis raziano de la idea de autoridad legítima como los ejes o postulados básicos de su teoría del derecho - estrechamente ligados a los resultados de aquel análisis se asientan en último término sobre un mismo núcleo conceptual: la idea de una estrategia indirecta para maximizar la conformidad con cierto conjunto de razones mediante el seguimiento directo de otras que en la deliberación práctica de un sujeto reemplazan a las primeras. Para captar adecuadamente el sentido de esa noción fundamental, es preciso enmarcarla dentro del análisis general de la estructura de los razonamientos prácticos que Raz nos propone. De ello me ocupo a continuación.

\subsection{El análisis raziano de la estructura de los razonamientos prácticos y sus} instrumentos conceptuales

$\mathrm{Al}$ examinar la teoría de las razones para la acción que Raz nos ofrece, ha de tenerse en cuenta que su propósito fundamental no es otro que el de introducir la noción de «razón excluyente». Y aunque para alcanzar ese objetivo es preciso recorrer una serie de pasos previos, bien puede decirse que en cada uno de ellos el análisis de Raz se limita al mínimo estrictamente necesario para hacer posible, en su momento, la introducción de aquella idea clave. Esa forma de proceder tiene como consecuencia que algunos de los problemas más básicos o fundamentales que rodean a la idea misma de una «razón para actuar» sean despachados de forma excesivamente sumaria (o incluso francamente deficitaria) ${ }^{21}$.

${ }^{21}$ Raz da por sentado, por ejemplo, que las razones para actuar son «hechos», si bien entiende por tal «aquello en virtud de lo cual enunciados verdaderos o justificados son verdaderos o justifícados», lo que supone hablar de «hechos» en un sentido peculiar que, entre otras cosas, incluye los «valores» (PRN, 1975/1990, pp. 17-18). Naturalmente, el hablar de los valores como «hechos» implica una toma de partido -no argumentada- en favor de la concepción general de las razones para actuar (cuando éstas se entienden como razones justificativas, y no como razones explicativas o motivos de la conducta de un agente determinado) como razones externas u objetivas, es decir, como razones que son válidas aunque nadie en el mundo las incluya en su conjunto de preferencias, porque su validez no es relativa a su aceptación por un agente (de manera que sería perfectamente posible evaluar las preferencias últimas o supremas de un individuo desde un punto de vista que no resulte ser meramente el conjunto de preferencias últimas de otro, sino una instancia independiente de ambos, exterior a ellos, objetiva).

Hay desde luego un modelo general alternativo que conecta conceptualmente la noción de razones para la acción a la idea de preferencias (de distintas clases o niveles). Para este segundo modelo todas las razones para actuar lo son desde el punto de vista de alguien, y todo lo que se diga al respecto se dice siempre 
Pero aunque estas carencias hayan de consignarse en el pasivo del análisis raziano, el intento de colmarlas queda fuera de los límites de este trabajo. Sólo mencionaré -y muy brevemente- los pasos que nos conducen hasta el concepto de razón excluyente, en el que pretendo concentrar mi atención.

En primer lugar, Raz nos propone varias definiciones básicas cuyo sentido se aclara en relación con la idea de razonamiento o inferencia práctica. A su juicio las razones para actuar son «hechos» ${ }^{22}$, y los enunciados que son descriptivos de «hechos» que constituyen razones para la realización de cierta acción por un determinado agente actúan como premisas de inferencias prácticas. El conjunto de «hechos» tomados en cuenta en una inferencia práctica válida cuyas premisas no sean redundantes constituye una razón completa para la acción a la que se refiere su conclusión. Ahora bien, entre todos esos «hechos» hay algunos respecto de los cuales creer en su existencia implica tener una actitud crítica práctica (no sería posible, por ejemplo, «creer en la existencia» de cierto valor sin aprobar eo ipso las acciones que lo promueven o materializan). Los «hechos» de este tipo constituyen razones operativas. Todos los demás hechos que, junto a las razones operativas, integran razones completas $-\mathrm{y}$ respecto de los cuales creer en su existencia es compatible con no tener ninguna actitud crítica práctica determinada-, constituyen razones auxiliares. ${ }^{23}$ La función de unas y otras dentro de un razonamiento práctico puede resultar más clara si se piensa en las primeras como en su «premisa mayor» y en las segundas como su «premisa menor»: los enunciados

desde un punto de vista (es decir, la afirmación de que algo constituye una razón para actuar es adscriptiva, no descriptiva). Eso es tanto como decir que no existe un punto arquimédico en el que situarse para contemplar y evaluar desde fuera - esto es, sin situarse uno ya en un punto de vista particular- si «verdaderamente» son razones para actuar. La opción en favor de una de estas dos concepciones generales, lejos de ser sencilla o de poder darse por supuestas en uno u otro punto de vista se acepta como razones para actuar. La opción en favor de una de estas dos concepciones generales, lejos de ser sencilla o de poder darse por supuesta en uno u otro sentido, depende de la forma en que resolvamos algunas cuestiones centrales de la filosofía general del discurso práctico en cuyo examen Raz no se interna. Por mi parte, he tratado de analizar sistemáticamente esas cuestiones generales en Bayón, 1991, parte I, a donde me permito remitir.

${ }^{22}$ Véase la nota anterior acerca del peculiar sentido que Raz atribuye a esta afirmación y que, a mi juicio, justifica la cautela de hablar entrecomilladamente de «hechos».

${ }^{23} P R N, 1975 / 1990$, pp. 22-25 y 33-35. Entre las razones operativas, Raz incluye -de manera un tanto imprecisa y asistemática- los deseos, intereses y valores (ibi, p. 34). No obstante ha de tenerse en cuenta, como se verá enseguida, que a su juicio también las normas son razones operativas, si bien de un tipo especial. 
descriptivos de las razones auxiliares transferirían la actitud crítica práctica de la premisa mayor a la conclusión, señalando qué acción en concreto se tiene una razón para ejecutar habida cuenta de la validez de cierta razón operativa y de determinadas circunstancias contingentes que hacen que, en un caso dado, realizar aquella acción sea la forma de actuar de acuerdo con dicha razón operativa.

Las razones para actuar -operativas o completas- se relacionan entre sí por su peso o fuerza respectivos: si entran en conflicto, la razón de más peso prevalece sobre la de fuerza menor. Una razón es concluyente si, en una situación dada, ninguna otra prevalece por peso sobre ella; absoluta, si nunca es el caso que otra razón prevalece sobre ella; y meramente prima facie si no es ni absoluta ni concluyente ${ }^{24}$. Como además -siempre ajuicio de Raz- un enunciado del tipo «hay una razón para que $x$ haga $\emptyset$ » equivale a otro como « $x$ debe hacer $\emptyset\rangle^{25}$, las distinciones que se acaban de presentar permitirían entender con facilidad las nociones de deber prima facie, deber concluyente (o «habida cuenta de todos los factores relevantes») y, eventualmente, deber absoluto.

Tomando en cuenta esta dimensión de peso o fuerza, la imagen resultante de la deliberación práctica sería la de un balance global en el que se sopesan todas las razones a favor y en contra de la acción acerca de cuya realización se delibera. De ese modo, resultaría aparentemente indiscutible -por tautológico- un principio meramente formal de la racionalidad práctica en virtud del cual siempre se debe hacer lo que se tiene una razón concluyente para hacer, esto es, lo que resulte en cada ocasión del balance global de razones a favor y en contra sopesadas según su fuerza relativa. A este principio aparentemente indiscutible se refiere Raz como $\left\langle\mathrm{P}_{1}\right\rangle^{26}$. Pero de lo que Raz va a intentar convencernos es de que, sean cuales fueren las apariencias, $\mathrm{P}_{1}$ resulta excesivamente simplista como para hacer justicia a la verdadera complejidad potencial de la racionalidad práctica.

${ }^{24}$ PRN, 1975/1990, pp. 25-28.

${ }^{25} P R N, 1975 / 1990$, p. 29. La afirmación, con todo, parece un tanto discutible: por un lado, no parece que esa equivalencia sea mantenible -a no ser en un sentido extraordinariamente lato de «deber», que no corresponde al uso ordinario- sea cual sea la naturaleza de la razón operativa que se afirma que concurre (y que puede ser, pongamos por caso, el mero interés del agente): por otro, no permite dar cuenta de la diferencia que mediaría entre un acto debido y uno supererogatorio (en favor de cuya realización, ciertamente, tiene que haber alguna razón, pero que no por ello se reputa debido).

${ }^{26}$ PRN, 1975/1990, p. 36. 
A juicio de Raz - que en este punto sigue ideas de Warnock ${ }^{27}-\mathrm{P}_{1}$ no permitiría entender el papel de las reglas en el razonamiento práctico. En su opinión no puede decirse con propiedad que alguien «acepta una regla» si reconsidera la totalidad de razones a favor y en contra de hacer lo que la regla establece en cada una de las ocasiones de aplicación de la misma, porque «tener una regla es como haber decidido de antemano qué hacer» ${ }^{28}$. En ese sentido, una regla no sería meramente una razón más para actuar, ni siquiera una que generalmente prevalece en cierta clase de situaciones ( $\mathrm{y}$ por ello mismo diferiría sustancialmente de un juicio de deber ordinario, que, siempre según Raz, equivaldría como ya sabemos a la afirmación de que hay cierta razón para actuar). El papel genuino de una regla consistiría en retirar o desplazar de antemano del razonamiento práctico de un agente un conjunto de posibles razones de signo contrario para todas y cada una de las ocasiones en las que la regla sea aplicable, de manera que la elección del agente para cada una de esas ocasiones quede prefigurada por la regla sin que proceda la reconsideración global caso por caso de la totalidad de razones concurrentes a favor y en contra. El razonamiento práctico en el que entran en juego reglas, en definitiva, no encajaría en el molde formal de $\mathrm{P}_{1}$.

Ahora bien, si aceptamos esa caracterización de la idea de regla, lo que no resulta tan claro es en qué sentido podría ser racional aceptar y seguir reglas; o lo que es lo mismo: en qué sentido podría sostenerse que apartarse de $\mathrm{P}_{1}$ no es necesariamente irracional. A juicio de Raz aceptar y seguir reglas puede ser racional (aunque no siempre lo es). Y para entender en qué sentido puede serlo habría que introducir la noción de «razones de segundo orden», puesto que sería la existencia de razones de segundo orden válidas la que determinaría que la racionalidad práctica no siempre quede confinada dentro de los márgenes de $\mathrm{P}_{1}$. Para entender este paso fundamental del análisis de Raz es preciso presentar toda una familia de conceptos nuevos.

Raz llama razones de primer orden a las razones para realizar o no realizar una acción. Las razones de segundo orden serían razones para actuar o no actuar por una razón de primer orden: en el primer caso se trataría de una «razón de segundo orden positiva»; en el segundo, de una «razón de segundo orden negativa» o razón excluyente. Una «razón protegida» sería aquella que es a la vez una razón de primer orden para $\emptyset$ y una razón excluyente

\footnotetext{
${ }^{27}$ Cfr. Warnock, 1971, pp. 46-47.
}

${ }^{28}$ PRN, 1975/1990, p. 73. 
para abstenerse de actuar por otras razones de primer orden en contra de $\emptyset^{29}$.

La distinción entre estas diversas clases de razones obligaría a trazar una tipología de los conflictos prácticos bastante más compleja que la que representa $\mathrm{P}_{1}$ que sólo sería apto para reflejar el modo en que se desenvuelven los conflictos entre razones de primer orden. En el esquema de Raz, una razón puede ser superada en peso por otra del mismo orden o excluida por otra de orden superior; y en este último caso la razón excluyente prevalecería sobre las razones de primer orden que excluye no en virtud de su mayor peso -como si una y otras hubiesen de ser sopesadas dentro de un mismo balance-, sino en virtud de un principio general del razonamiento práctico a tenor del cual las razones para no actuar por otras razones prevalecerían siempre sobre éstas en el sentido de que las últimas quedarían retiradas o desplazadas de la consideración del agente por las primeras ${ }^{30}$.

Dos datos suplementarios complican aún más la tipología de los conflictos prácticos. En primer lugar, nos advierte Raz, las razones excluyentes tienen un alcance [scope]: lo que eso significa es que una razón excluyente válida puede excluir sólo una parte, y no la totalidad, de las razones de primer orden relevantes, de manera que el alcance de una razón excluyente es el conjunto de razones de primer orden que excluye ${ }^{31}$. Si es además una «razón protegida», el conflicto entre ella en su dimensión de razón de primer orden y las razones de primer orden que no excluye -i.e., que quedan fuera de su alcancese decide en términos de peso o fuerza con arreglo a $\mathrm{P}_{1}$. Y en segundo lugar, también serían concebibles conflictos entre razones de segundo orden de signo contrario, que se decidirían en términos de peso o fuerza ${ }^{32}$. De cualquier razón no superada en peso por otra del mismo orden ni excluida por otra de orden superior podríamos decir que es una razón «no derrotada» [undefeated]. Y con todos estos elementos a la vista habríamos de concluir que la racionalidad práctica no queda definida necesariamente por $\mathrm{P}_{1}$ dada la validez de un principio complementario $-\mathrm{P}_{2}-$ que cabría formular como «no se debe actuar según el balance de razones si las razones que lo deciden son excluidas por una razón excluyente no derrotada». Y si quisiéramos extraer un principio aplicable por igual a las situaciones en las que es válido $\mathrm{P}_{1} \mathrm{y}$ a aquéllas en las que es válido $\mathrm{P}_{2}$,

\footnotetext{
${ }^{29}$ PRN, 1975/1990, p. 39; Raz, 1982, pp. 32-33.

${ }^{30} P R N, 1975 / 1990$, pp. 40 y $45-47$.

${ }^{31} P R N, 1975 / 1990$, pp. 40 y 46.

${ }^{32} P R N, 1975 / 1990$, p. 47.
} 
obtendríamos $\mathrm{P}_{3}$ : «siempre es el caso que uno debe, habida cuenta de todos los factores relevantes, actuar por una razón no derrotada». La verdadera racionalidad práctica consistiría según Raz en actuar siempre de acuerdo con $\mathrm{P}_{3}$, lo que sólo algunas veces -a saber: cuando no entraran en juego razones de segundo orden válidas- equivaldría a actuar según $\mathrm{P}_{1}{ }^{33}$.

Ahora ya es posible entender en qué sentido quien acepta una regla $y$ consiguientemente se aparta de $\mathrm{P}_{1}$, no sería necesariamente irracional. Para Raz las reglas son razones excluyentes (aunque no todas las razones excluyentes son reglas) ) $^{34}$ y sólo puede decirse que acepta una regla de aquel agente que la considera una razón excluyente. En su opinión, una regla -a diferencia de lo que sucedería con un juicio de deber ordinario- no expresa que hay una razón para realizar cierta acción, sino que es ella misma una razón de cierta clase especial (generalmente, aunque no siempre, una razón protegida ${ }^{35}$ ). Conviene de todos modos introducir dos tipos de precisiones respecto al sentido en el que Raz afirma que las reglas son razones para actuar (de esa clase especial).

En primer lugar, se ha de recordar que según Raz cabe distinguir entre lo que verdaderamente es y lo que alguien cree que es una razón para actuar, entre razones que son válidas y razones que alguien considera válidas (acertada o desacertadamente). Si una regla no es más que un tipo especial de razón, habrá reglas válidas (incluso si nadie las considera como tales) y reglas que no lo son (con independencia de que alguien -o muchos; o todos- las considere válidas) ${ }^{36}$. Eso es tanto como decir que no todo el que acepta una regla es racional al hacerlo: lo será si realmente la regla es una razón excluyente válida. Lo que Raz sostiene no es meramente que de facto haya sujetos que consideren válidas ciertas razones excluyentes: lo que sostiene es que hay razones excluyentes válidas (si la clase de las «razones excluyentes válidas» constituyera un conjunto vacío, el concepto carecería obviamente de interés), aunque ciertamente el conjunto de todas las que lo son

${ }^{33} P R N, 1975 / 1990$, p. 40.

${ }^{34}$ PRN, 1975/1990, pp. 77-78; también lo serían, según Raz, las decisiones, órdenes, promesas...

${ }^{35} P R N, 1975 / 1990$, p. 77.

${ }^{36} P R N, 1975 / 1990$, pp. 80-81. Hablar en este contexto de reglas válidas equivale a hablar de razones (de un tipo especial) válidas, esto es, de reglas que es racional o está justificado aceptar. Por consiguiente no se habla aquí de «validez» en ningún sentido intrasistémico, como el empleado al decir que una norma pertenece a cierto sistema normativo, o que su emisión ha sido correcta de acuerdo con los criterios que el propio sistema estipula, o que puede afirmarse lo primero porque ha sucedido lo segundo. 
no sea coextenso con el conjunto de todas las que son consideradas como tales. Por consiguiente el actuar de acuerdo con una razón excluyente válida diferiría radicalmente de la decisión irracional y arbitraria -esto es, no respaldada por una razón de segundo orden válida- de no actuar por una razón de primer orden válida.

Por otra parte, es preciso deslindar con cuidado los diversos significados posibles de un enunciado que afirma que «existe» tal o cual regla. Con ello se podría querer decir, en primer lugar, que esa regla es una razón - por lo general, protegida- válida (o si se quiere: que es verdaderamente una razón para actuar de ese tipo especial). En segundo lugar, que esa regla es efectivamente practicada, es decir, que se da el hecho social complejo de que la generalidad de los miembros de un grupo la considera válida (acertada o desacertadamente) y actúa normalmente de acuerdo con ella, Raz no pretende en absoluto que el hecho de que exista una regla social en este último sentido constituya una razón para actuar: se tendrá una razón para actuar sólo si la regla efectivamente practicada es válida. Ciertamente en algunos casos - como sucedería con las convenciones que resuelven problemas de coordinación- el hecho de que la regla sea practicada es relevante para su validez: pero cualquiera que sea el número de las reglas cuya validez dependa de que sean practicadas, habría reglas válidas aunque no sean practicadas y reglas practicadas que no por ello son válidas. Y el mismo tipo de reflexiones podría aplicarse cuando decimos que «existe» una regla queriendo decir que ha sido prescrita por alguien (una «autoridad normativa»), sea o no practicada por el grueso del grupo quien emite la norma pretendería que fuese considerada por sus destinatarios como una razón excluyente válida ( $\mathrm{y}$, correlativamente, se aceptaría la autoridad de alguien cuando se entendiera que hay una razón excluyente válida para hacer lo que ordena hacer). Pero, de nuevo, que alguien considere válida $-o$ pretenda que otros consideren válida- una razón excluyente es una cosa, y otra muy distinta que verdaderamente sea válida; y por consiguiente para Raz las reglas emitidas por una autoridad no constituyen necesariamente razones - protegidas- válidas para la acción ${ }^{37}$.

Una vez familiarizados con el aparato conceptual que maneja Raz, creo que resulta evidente la ligazón entre su análisis de la estructura de los razonamientos prácticos, su concepción de la autoridad legítima y su caracterización del derecho en tanto que sistema normativo de un tipo especial. Y también resulta obvio

${ }^{37}$ PRN, 1975/1990, pp. 80-84. 
que el pilar sobre el que se asienta toda esa construcción no es otro que el concepto de razón excluyente. Me parece, sin embargo, que hay motivos fundados para poner en tela de juicio ese basamento.

\section{Crítica del concepto de razón excluyente}

2.1. Dos sentidos de "razón excluyente"

La idea de una «razón excluyente válida» tiene algo de desconcertante, dado que, si existen ciertas razones válidas para actuar, no es fácil comprender en qué sentido puede ser verdaderamente racional no actuar por dichas razones (o con otras palabras: en qué sentido, distinto del de ser meramente otra razón más del mismo tipo que prevalece sobre ellas por su peso o fuerza, podría haber una razón válida para no actuar por dichas razones). Consciente de ello y para disipar ese aire de paradoja -que no ha dejado de ser señalado y explotado por sus críticos-, Raz ha replanteado globalmente el sentido de la noción de razón excluyente en el apéndice a la segunda edición de $P R N$. Comenzaré examinando los términos de esta reciente reformulación, de la que a mi juicio emerge un concepto de razón excluyente mucho más claro y mejor perfilado -aunque está por ver si es o no aceptable- que el que cabía extraer de escritos anteriores (y especialmente de la primera edición de $P R N$ ). $A$ continuación, no obstante, intentaré demostrar que, en contra de lo que pretende el propio Raz, a lo largo de su obra no siempre se ha manejado la idea de razón excluyente con ese preciso sentido.

a) En su reciente reformulación Raz parte de una distinción básica: si p es una razón para $\emptyset$, «se actúa de acuerdo con p» cuando se hace $\emptyset$, cualquiera que haya sido el motivo del agente para hacerlo, mientras que «se actúa por p» cuando no sólo se hace $\emptyset$, sino que además el agente lo ha hecho precisamente motivado por p. En el primer caso hay «conformidad» [conformity] con una razón para actuar; en el segundo, hay además «cumplimiento» [compliance] o seguimiento de la misma. Sentada esta distinción, que me parece razonablemente clara, Raz da un paso más y afirma que las razones para actuar son con carácter general razones para la conformidad, no para el seguimiento ${ }^{38}$, lo que es tanto como decir que uno hace todo lo que tiene una razón para

${ }^{38}$ PRN, 1990, p. 180. 
hacer -i.e., todo lo que es racional- si actúa «de acuerdo con» las razones aplicables al caso, aunque no actúe «por» ellas. Ésa es sin duda una afirmación controvertible (y que, referida al caso de las razones morales, ciertamente no podría ser compartida por un kantiano, como el propio Raz reconoce ${ }^{39}$ ); pero, sea como fuere, Raz va a hacer de ella la clave para la defensa de la idea de una «razón excluyente válida».

Porque en efecto, en lo que Raz insiste es en que hay ocasiones en las que el modo de hacer más probable la conformidad con un conjunto de razones radica justamente en no actuar por ellas, es decir, en la adopción de una estrategia indirecta que busca asegurar la conformidad con las mismas por una vía distinta de su seguimiento. Y ese sería en realidad el modo en el que habría que entender la relación entre una razón excluyente y el conjunto de razones excluidas por ella: la razón excluyente sería una razón «para no actuar por» las razones -subyacentes- excluidas (esto es, una razón para no actuar motivado por ellas, para no intentar hacer de nuestra apreciación de lo que exigen la guía directa de nuestra acción), sin que ello implique en modo alguno el que sea una razón «para no actuar de conformidad con» dichas razones. Todo lo contrario: las razones subyacentes excluidas son y seguirían siendo, en tanto que determinantes de la acción correcta, razones válidas y por consiguiente sería irracional no «actuar de acuerdo con ellas»; lo que ocurre es que, al mismo tiempo, también sería irracional «actuar por ellas» si verdaderamente cabe afirmar que el hacerlo es una estrategia peor para alcanzar en definitiva la conformidad con las mismas que el actuar por la razón excluyente (y precisamente por eso, y sólo por eso, es por lo que podría decirse que ésta es válida $)^{40}$. En suma; el papel de las razones excluyentes válidas no sería otro que el de servir de vías indirectas para maximizar la conformidad con las razones subyacentes que excluyen, reemplazando a éstas como motivaciones correctas del agente (no como determinantes de la acción correcta).

Esta forma de entender la relación entre una razón excluyente y las razones excluidas por ella -que obviamente está modelada en los mismos términos que la concepción raziana de la autoridad legítima «como servicio»- imprime también un determinado signo a la noción más compleja de «razón protegida». Ha de recordarse que para Raz las directivas de una autoridad legítima no son sólo razones excluyentes, sino también al mismo tiempo razones de primer orden para realizar cierta acción (la acción ordenada),

${ }^{39}$ PRN, 1990, pp. 181-182.

${ }^{40} P R N$, 1990, pp. 185, 190 y 194. 
siendo precisamente esa combinación de razón excluyente y razón de primer orden la que constituye la «razón protegida» ${ }^{41}$. Ahora bien, cuando la idea de razón excluyente se entiende del modo descrito - esto es, como estrategia indirecta hacia la conformidad con un conjunto de razones subyacentes-, lo coherente es concebir esa razón de primer orden que es también la razón protegida como razón «dependiente» [dependent] y «sustitutiva» [pre-emptory], es decir, como una razón de primer orden que intenta reflejar el resultado del balance del conjunto de razones de primer orden excluidas (y que por eso es «dependiente» de éstas) y que ocupa su lugar en la deliberación del agente (las «sustituye») $)^{42}$. De lo que se trata, en definitiva, es de actuar de acuerdo con las razones subyacentes excluidas y de hacerlo, como mejor estrategia posible, no actuando directamente por ellas -es decir, intentando el agente determinar por sí mismo qué resulta de su balance-, sino deponiendo o postergando el propio juicio y actuando simplemente por la razón protegida (entendiendo que la conformidad con ésta en tanto que razón de primer orden equivaldría a la conformidad con el resultado del balance de las razones subyacentes excluidas).

Decir de la directiva de una autoridad legítima que es, en tanto que razón de primer orden, una razón dependiente y sustitutiva es tanto como decir que la emisión de dicha directiva no modifica en absoluto el balance de razones de primer orden aplicables al caso, no «genera» ninguna razón nueva que se añade al conjunto de las ya existentes. O dicho con términos más técnicos cuyo significado ya conocemos: si la razón protegida es, en tanto que razón de primer orden, una razón dependiente y sustitutiva el resultado del balance de razones de primer orden anterior a la emisión de la directiva será el mismo que el del balance de razones «no derrotadas» con posterioridad a dicha emisión (puesto que la razón de primer orden dependiente y sustitutiva pretende reflejar el resultado del balance de razones de primer orden preexistentes, entenderla como una razón nueva que viene a añadirse a ese balance -y por tanto a alterarlo- supondría contar dos veces las razones que prevalecen en él).

En suma, la concepción de las razones excluyentes como vías indirectas para maximizar la conformidad con las razones subya-

${ }^{41}$ De hecho, Raz no destaca ningún caso típico o interesante de razón excluyente que no sea a la vez una razón protegida. En $P R N, 1975 / 1990$, p. 77, menciona -meramente de pasada- un ejemplo de esa posibilidad, construido por lo demás, según creo, en términos escasamente convincentes.

${ }^{42}$ Cfr. Raz, 1989, pp. 160-161; y Raz, 1986, pp. 57-62. 
centes que excluyen, reemplazando a éstas como motivaciones del agente, es coherente con la concepción de las razones protegidas, en su dimensión de razones de primer orden, como razones dependientes y sustitutivas. Este esquema, sin embargo, no es fácilmente trasladable a todos los contextos en los que Raz recurre al concepto de razón excluyente, ni creo que casen con él algunas ideas que en ocasiones ha mantenido expresamente en relación con el mismo.

b) Pensemos, por ejemplo, en el caso de las promesas, que también son a juicio de Raz razones protegidas. Parece evidente que la prestación de una promesa genera una nueva razón para actuar que no existía previamente. De qué modo se «genera» exactamente esa nueva razón es algo que debería ser explicado con mayor detenimiento $-\mathrm{y}$ a lo que me referiré más adelante-, pero ahora lo que interesa es determinar cómo se relaciona la nueva razón creada con el resto de razones («de primer orden») preexistentes. Una primera posibilidad sería desde luego entender que se trata de otra razón más de primer orden que habrá de ser sopesada con el resto dentro de un balance global (en la terminología raziana, estaríamos entonces ante un conflicto que se desenvuelve en los términos de $\mathrm{P}_{1}$ ). Ahora bien, si aceptamos, con Raz, que las promesas son «razones protegidas»-i.e., razones de primer orden que son a la vez razones excluyentes-, habría que entender que el «desplazamiento» de razones preexistentes por la nueva razón creada equivale a la exclusión de razones de primer orden por otra de segundo orden (para no actuar por ellas), no simplemente al hecho de que, entre razones del mismo tipo, la que ahora se añade al balance pueda eventualmente prevalecer por su peso o fuerza sobre las demás.

Obsérvese, sin embargo, que en este caso el concepto de «razón protegida» no tiene la misma estructura que se acaba de analizar hace un momento. En tanto que razón de primer orden, no cabe decir ahora de ella que es «dependiente y sustitutiva» (el resultado del balance de razones de primer orden con anterioridad a la prestación de la promesa no tiene ya por qué coincidir con el del balance de razones no derrotadas con posterioridad a la misma); y no parece que aquí encaje bien -o mejor: parece que no encaja en absoluto- la concepción de las razones excluyentes como vías indirectas para maximizar la conformidad con las razones subyacentes que excluyen, puesto que de hecho, en el caso que ahora nos ocupa, la razón excluyente no lo es sólo para no «actuar por» las razones que excluye, sino que perfectamente puede serlo también -y lo será en muchas ocasiones- para no «actuar de conformidad con» dichas razones excluidas (con otras 
palabras: la conformidad con la razón protegida en tanto que razón de primer orden no tiene ya por qué equivaler a la conformidad con el resultado del balance de las razones excluidas; y por consiguiente poco sentido tendría afirmar que el seguimiento de la razón protegida constituye «la mejor estrategia» para asegurar la conformidad con aquéllas).

En definitiva, me parece que andan en juego dos formas distintas de entender la relación entre una razón excluyente y las razones excluidas por ella ${ }^{43}$. De hecho, puede detectarse en los textos de Raz una oscilación que, lejos de constituir un detalle trivial, me parece reveladora de la ambigüedad mencionada. En la más reciente reformulación raziana, una razón protegida se define como la combinación de una razón para realizar cierta acción y una razón excluyente para no actuar por ciertas razones a favor o en contra de aquella acción ${ }^{44}$; en ocasiones anteriores, sin embargo, la había definido como la combinación de una razón para realizar cierta acción y una razón excluyente para no actuar por ciertas razones en contra de dicha acción $\mathrm{n}^{45}$. No creo que la diferencia entre ambas formulaciones sea meramente fruto del descuido. En efecto, cuando las razones excluyentes se conciben como estrategias indirectas para maximizar la conformidad con las razones subyacentes excluidas carecería de sentido decir que lo que excluyen son sólo las razones en contra de la acción para la que existe una razón protegida: puesto que se trata de razones para que el agente no intente hacer de su apreciación de lo que exige el balance de las razones subyacentes la guía directa de su acción, son éstas en su conjunto las que quedan excluidas -como motivaciones correctas del agente, no como determinantes de la acción correcta-, tanto si son a favor como si son en contra de la acción para la que existe la razón protegida.

Entender, por el contrario, que lo queda «excluido» es únicamente un cierto conjunto de razones en contra de la acción para la que existe la «razón protegida», supone no sólo manejar un sentido diferente de la idea de razón excluyente, sino uno, además, cuya necesidad teórica o conceptual no alcanza a verse con claridad. Que la concepción de las razones excluyentes como estrategias

${ }^{43}$ Esta ambigüedad ha sido señalada, en términos parecidos aunque no exactamente coincidentes con los que aquí se han expuesto, por Moore, 1989, p. 854: para Moore, un sentido de la idea de razón excluyente tendría que ver con la estrategia o procedimiento correcto que el agente ha de seguir para tomar una decisión; otro, con los elementos que hacen correcta su decisión y la eventual alteración de la estructura de esos elementos.

${ }^{44}$ PRN, 1990, p. 191.

${ }^{45}$ PRN, 1975/1990, pp. 58-59; Raz, 1982, pp. 32-33. 
indirectas para maximizar la conformidad con las razones que excluyen sea o no aceptable dependerá de si se consigue o no demostrar, en primer lugar, que hay efectivamente circunstancias en las que el intento del agente de actuar con arreglo a su propio juicio acerca de lo que exigen las razones subyacentes resulta auto-frustrante; y en segundo lugar, que en esas circunstancias el actuar por lo que se nos presenta como «razones protegidas» supone verdaderamente una estrategia mejor para acabar actuando a la postre de conformidad con aquellas razones. Que ambos extremos sean o no demostrables es algo que está por ver. Pero al menos, entendidas de ese modo, se percibe con claridad en qué sentido las «razones excluyentes válidas» - caso de haberlas- representarían en el discurso práctico un fenómeno completamente distinto del de las razones de primer orden.

Por el contrarío, cuando las razones excluyentes se conciben en el segundo de los sentidos examinados, no me parece nada claro por qué hay que calificar como «exclusión» el «desplazamiento» de algunas de las razones preexistentes llevado a cabo por la nueva razón surgida; por qué hay que decir que ha sido creada una «razón protegida», y no meramente una nueva razón de primer orden con una determinada fuerza; qué necesidad teórica habría en esos casos de acudir a la idea de razón excluyente y cuál sería la diferencia real con una explicación en términos de $\mathrm{P}_{1}$; en suma, qué diferencia se supone que hay entre una «razón excluyente» -en este segundo sentido- y una razón de primer orden con peso suficiente para superar exactamente las mismas razones que la presunta razón excluyente excluye $^{46}$ (habida cuenta,

${ }^{46}$ Como criterio general que presuntamente marcaría con claridad la diferencia entre una y otra Raz propone lo que denomina «test de las reacciones mixtas» (PRN, 1975/ 1990, pp. 41-45 y 74-75). Si estamos ante un conflicto entre razones de primer orden -nos dice-, nuestras reacciones son inequívocas: no dudarnos en censurar a quien actúa por una razón desbancada por otra de mayor peso ni en considerar correcta la acción realizada de conformidad con ésta. Por el contrario, una característica ambivalencia en nuestras reacciones críticas sería el indicio de la presencia de una razón excluyente. Y esa ambivalencia provendría, cuando interviene una razón de esta clase, de la separabilidad de dos planos de evaluación: cuando alguien desatiende una razón excluyente válida y hace lo que resulta del balance de razones de primer orden, aun criticándole por ello no dejamos de pensar que en cierto sentido parcial actuó bien, que había razones para hacer lo que hizo; y a la inversa, cuando alguien actúa de acuerdo con una razón excluyente válida y, precisamente por ello, deja de hacer lo que es correcto según el balance de razones de primer orden, nuestra aprobación arrastra consigo a pesar de todo la insatisfacción de que, también en cierto sentido parcial, se debería haber actuado de otro modo. En mi opinión, sin embargo, la presencia de «reacciones mixtas» ni tiene por qué ser pertinente en todos los casos en los que a juicio de Raz intervienen razones excluyentes ni es exclusiva 
además, de que de toda razón que prevalece por su peso sobre otra parece que cabría decir, en algún sentido, que es una razón para no actuar por esta última).

Parece más bien que cuando se habla de razones excluyentes en este segundo sentido nos encontramos en realidad ante una forma resumida de argumentar en la deliberación práctica, es decir, ante formas abreviadas de presentación de conjuntos de razones de primer orden que típicamente concurren en ciertas clases de situaciones y que, como tales formas abreviadas, tienen naturalmente la misma fuerza que ese conjunto de razones cuya existencia expresan sintéticamente. Aunque demos en llamar «razones excluyentes» a esas formas sintéticas de presentación, el conjunto de razones adversas que «excluyan»-en términos razianos: su «alcance»- no podrá sino ser idéntico a aquél sobre el que prevalezca por peso el conjunto de razones cuya existencia expresan abreviadamente. $\mathrm{Y}$ en ese caso, naturalmente, el concepto de razón excluyente resulta ser perfectamente prescindible desde el punto de vista teórico.

En conclusión, creo que la noción de razón excluyente tiene su asiento natural en conexión con la idea de estrategia indirecta para la conformidad con las razones excluidas. Fuera de ese terreno se desdibuja, se antoja teóricamente superflua. Las dos concepciones examinadas aparecían entremezcladas en los primeros textos de Raz, que, por consiguiente, hacía a mi juicio un uso ambiguo del concepto al utilizarlo para dar cuenta de la estructura de contextos de deliberación práctica muy diferentes entre sí. En sus elaboraciones más recientes, por el contrario, el sentido del concepto se ha ido depurando hasta perfilarlo en la dirección que se ha señalado. Falta ahora por ver si realmente puede admitirse que hay «razones excluyentes válidas» como estrategias indirectas para la conformidad con las razones subyacentes que excluyen. Raz no articula realmente una explicación general al respecto, sino que se limita a aludir a dos contextos o conjuntos de circunstancias en los que entiende que dicha demostración es posible. Pero antes de analizarlos $-\mathrm{y}$ para contar, entre otras cosas, con los instrumentos conceptuales necesarios para enjuiciarlos-, me parece conveniente introducir dos nociones que representan otras tantas complicaciones o refinamientos dentro de una teoría de las razones para la acción, ninguna de las cuales, sin embargo, nos obliga a rebasar los términos de $\mathrm{P}_{1}$, (es decir, ninguna de las cuales

de las mismas (piénsese, por ejemplo, en el caso de genuinos dilemas morales en los que no intervengan ninguno de los fenómenos que Raz califica como razones excluyentes). 
supone dar entrada a la categoría de «razones de segundo orden»).

2.2. Una reconstrucción conceptual alternativa: "reglas indicativas" $y$ "razones independientes del contenido"

a) Si se afirma que la decisión racional es en cada caso la que resulte de contrapesar todas las razones («de primer orden») a favor y en contra - es decir, que el proceso de toma de decisiones racionales se desenvuelve por definición con arreglo a $\mathrm{P}_{1}-$, parece que se está dando por supuesto que la deliberación práctica se desarrolla en condiciones de información completa y de ausencia de costes de decisión. Pero naturalmente no siempre se dan esas condiciones. En ocasiones el agente sabe que su información no es completa o no es fiable (esto es, sabe que no sabe todo lo necesario para determinar sin error qué resulta del balance de razones); o, dado que la determinación del resultado del balance requiere tiempo y esfuerzo -o lo que es lo mismo: entraña un coste-, puede darse el caso de que los costes de decisión excedan del beneficio marginal que resulte de desarrollar una deliberación completa.

Suele afirmarse que lo que en esas circunstancias le recomienda la racionalidad práctica al agente $-\mathrm{o}$ incluso le impone, en la medida en que cualquier otro proceder resultaría subóptimo- es seguir una «regla de experiencia» [rule of thumb] en tanto que mecanismo de minimización de errores en condiciones de incertidumbre y de ahorro de tiempo y esfuerzo. El problema consiste en determinar con mayor precisión qué son y cómo operan exactamente esas «reglas de experiencia», de qué modo encajan dentro del panorama global de las razones para actuar. Lamentablemente, aunque la utilización del término es relativamente corriente su sentido dista mucho de estar claro, hasta el punto de que hay quien, como Hare, propone sin ambages que deje de utilizarse por parecerle «totalmente desorientador $\gg{ }^{47}$. No obstante, Donald Regan ha propuesto recientemente una cierta forma de entender las «reglas de experiencia» que me parece perfectamente aprovechable ${ }^{48}$.

Para Regan, las «reglas de experiencia» funcionan en la deliberación práctica como «reglas indicativas» [indicator rules]. Las misleading»].

${ }^{47}$ Hare, 1981, p. 38 [«The term 'rules of thumb'... should be avoided as thoroughly

${ }^{48}$ Cfr. Regan, 1989, pp. 1004-1013. 
reglas indicativas serían generalizaciones extraídas a partir de conjuntos de decisiones tomadas en condiciones de información completa, es decir, compendios o sumarios de decisiones de casos particulares, que permitirían afirmar, por ejemplo, que en los casos de la clase $p$ la acción correcta suele ser $\emptyset$ porque en ellos prevalece típicamente tal o cual razón. Cuando el agente sabe que no está en condiciones de determinar cuál es la conclusión correcta de sopesar todas las razones relevantes dentro de un balance global; sabe al menos con seguridad que el caso que le ocupa puede ser descrito como uno de la clase $p$; y es acertada la generalización según la cual lo correcto en esa clase de casos suele ser $\emptyset$, entonces sabe que su probabilidad de hacer lo correcto es mayor si realiza $\emptyset$ que si ejecuta cualquier acción alternativa (esto es, la regla «en los casos de la clase $p$ se debe hacer $\emptyset$ » le indica cuál es con un mayor índice de probabilidad la acción correcta).

Por supuesto las reglas indicativas son falibles: en la medida en que indican lo que suele ser correcto en cierta clase de situaciones, no lo que siempre es correcto en ellas, nada garantiza que el caso acerca del cual se decide no resulte ser uno de aquellos en los que la acción correcta es otra distinta. Pero a pesar de todo hay un sentido en el que cabe decir con toda propiedad que son vinculantes: cuando el agente sabe que no sabe lo que resulta del balance de razones, la racionalidad práctica le exige adoptar aquel procedimiento de decisión que, aun falible, cuente con las mayores probabilidades de aproximarle a la decisión correcta, de manera que afirmar que las reglas indicativas son «vinculantes» es tanto como decir que seguir en esas circunstancias cualquier otro procedimiento de decisión subóptimo constituye un déficit de racionalidad. Las reglas indicativas son además revisables o provisionales, en tanto en cuanto el sentido en el que son «vinculantes» exige de ellas el que sean la mejor o más fina generalización de conjuntos de decisiones tomadas en condiciones de información completa de que dispone en cada caso el agente.

Pero sobre todo - subraya Regan- las reglas indicativas no son ni «absolutamente transparentes» ni «absolutamente opacas». Un individuo trata una regla como «absolutamente transparente» si considera que sólo es racional hacer lo que la regla establece cuando se tiene la plena certeza de que ésa es efectivamente la acción correcta para el caso según el balance global de razones. En esas condiciones la regla realmente no contribuye por sí misma en nada al proceso de toma de decisión: no pasa de ser un punto de partida para la deliberación, pero si el agente entiende que para guiar su acción necesita ver a través de la regla y más allá de ella cuál es verdaderamente la acción correcta según el balance 
de razones está claro que, en caso de duda acerca de este extremo, no considerará a la regla misma como una guía práctica adecuada. Las reglas indicativas no son absolutamente transparentes: guían al agente «sin tener a la vista» en su integridad el balance de razones y su conclusión, proporcionándole la que es en esas condiciones la más racional (aunque no infalible) orientación para su acción.

En el extremo opuesto, un agente trata una regla como «absolutamente opaca» si considera que ha de hacer en todo caso lo que la regla establece con independencia de lo que resulte en cada situación del balance de razones y de su eventual conocimiento de ese resultado (es decir, el proceso de toma de decisión queda guiado exclusivamente por la regla, sin atender a las razones verdaderamente aplicables al caso que el agente pudiera tener a la vista y que, en ese sentido, resultarían «tapadas» por aquélla). Las reglas indicativas no son absolutamente opacas: guían al agente cuando éste no sabe con certeza cuál es la acción correcta según el balance de razones, pero no cuando tiene a la vista elementos de juicio que en un caso determinado le permiten darse cuenta con seguridad de que la acción correcta según el balance de razones no es la que la regla establece. En ese caso la regla indicativa ha de ser simplemente ignorada (i.e., las reglas indicativas carecen de cualquier valor en condiciones de información completa).

En mi opinión resulta claro que adoptar y seguir «reglas de experiencia» como reglas absolutamente transparentes sería inútil y que adoptarlas como reglas absolutamente opacas sería irracional; y por consiguiente que sólo pueden tener un encaje aceptable dentro del panorama global de las razones para actuar entendidas como reglas indicativas. Ahora bien, entendidas del modo descrito, creo que las reglas indicativas no son en sí mismas -y en sentido estricto- razones para actuar, sino razones para creer: en concreto, para creer en situaciones de incertidumbre que cierto curso de conducta es con la mayor probabilidad el que uno tiene razones para ejecutar. Se trata, eso sí, de una clase especial de razones para creer, con incidencia inmediata en la esfera práctica, porque, como sintéticamente dice Nino, «tenemos razones para hacer aquello que tenemos razones para creer que tenemos razones para hacer ${ }^{49}$. Pero una estrategia racional para incrementar en situaciones de incertidumbre la probabilidad de hacer lo correcto según el balance de razones aplicables al caso no equivale en absoluto a una razón que compita con éstas, ni mucho menos a

${ }^{49}$ Nino, 1989 b, p. 133. 
una que justifique no tomarlas en cuenta cuando el agente tenga conciencia clara de ellas como para colegir que lo que la regla establece no es en un caso determinado la acción correcta según el balance de razones.

Eso es tanto como decir que si las reglas indicativas no son en sentido estricto razones para actuar, menos aún son «razones para no actuar por otras razones», o «para no actuar según lo que resulta del propio juicio acerca de los méritos del caso». Lo que el agente puede tener son razones para no confiar en el acierto de su evaluación, es decir, razones para creer que sus elementos de juicio son incompletos o pueden ser erróneos: pero resultaría del todo inapropiado afirmar que la regla indicativa es «una razón para no actuar según el propio juicio acerca de los méritos del caso», porque en esa situación el juicio propio consiste precisamente en tener la certeza de que no se sabe-o, al menos, en no tener la certeza de que se sabe- qué resulta de los méritos del caso. Por el contrario, cuando el agente tiene razones suficientes para creer que su evaluación del balance de razones es correcta, resultaría irracional sostener que alguna regla indicativa a es a pesar de todo una razón para no actuar con arreglo a esa evaluación. En suma, aunque la toma en consideración del concepto de regla indicativa enriquezca la caracterización de la racionalidad práctica en términos de $\mathrm{P}_{1}$, no creo que nos fuerce en modo alguno a aceptar como herramienta conceptual la noción de «razón excluyente».

b) En el caso central o paradigmático de razón para actuar, cuando decimos que hay una razón para ejecutar cierta acción $\emptyset$ lo que estaríamos diciendo es que esa razón tiene que ver con el valor intrínseco del tipo de acción que es $\emptyset$. En ese supuesto podríamos hablar de razones «dependientes del contenido», puesto que, como dice Hart, «entre la razón y la acción existe una conexión de contenido» ${ }^{50}$. En otros casos, por el contrario, tendríamos cierto tipo de razones para realizar una acción que no tendrían nada que ver con «la naturaleza o carácter» ${ }^{51}$ de la misma, que no estarían ligadas intrínsecamente a la clase de acción justificada. Según autores como Hart o Raz, cuando se ha prometido $\emptyset$, o cuando una autoridad ha ordenado $\emptyset$, tendríamos una razón para $\emptyset$ cualquiera que sea -al menos, se supone, dentro de ciertos límites- la acción a la que estarnos llamando «Ø», esto es, una razón para actuar que no descansa en el valor intrínseco o directo de la clase de acción que sea $\emptyset$ y que se ha generado simplemente en virtud de haberse ejecutado ciertos

\footnotetext{
${ }^{50}$ Cfr. Hart, 1982, p. 255.
}

${ }^{51}$ Hart, 1982, p. 254. 
actos ilocucionarios (en el marco de determinadas prácticas o instituciones sociales) a los que se supone capaces de alterar la situación desde el punto de vista práctico. Y a esa clase de razón podríamos denominarla «independiente del contenido», ya que «no hay conexión directa entre la razón y la acción para la cual es una razón $»^{52}$. Promesas o mandatos de autoridad serían por tanto casos típicos -aunque no exclusivos- de razones independientes del contenido, de razones para realizar (en principio) toda clase de acciones sin que éstas necesiten tener otro rasgo en común más que, justamente, el hecho de haber sido prometidas, ordenadas, etc.

Construida en estos términos, no obstante, la distinción entre ambas clases de razones tropieza a mi juicio con dos dificultades. En primer lugar, el haberse prestado una promesa o el haberse dictado una orden son hechos, cuyo acaecimiento, además, es compatible con «no tener ninguna actitud crítica práctica determinada» en relación con las acciones prometidas u ordenadas, es decir, hechos que sólo pueden ser tomados en cuenta en un razonamiento práctico como razones auxiliares y que por consiguiente para justificar acciones necesitan del concurso de alguna razón operativa que les dé relevancia práctica y que, junto con ellos, integre una razón completa. En suma, tal y como ambas nociones han sido presentadas, mientras las razones «dependientes del contenido» serían genuinas razones operativas, lo que se nos ha presentado como razones «independientes del contenido» -promesas, mandatos, etc.- serán en todo caso razones auxiliares, es decir, ingredientes de razonamientos prácticos necesariamente más complejos.

En cuanto a la segunda dificultad, no existe algo que pueda ser llamado «la» descripción «natural» de una acción: todo acto individual (act-token) es susceptible de diversas descripciones, es decir, puede ser presentado como caso de múltiples actos genéricos (act-types), de modo que todo lo que digamos acerca del «contenido», «naturaleza» o «carácter» de una acción es relativo a una determinada descripción de la misma. Ello crea la sospecha de que calificar una razón como dependiente o independiente del contenido, si estas nociones se interpretan del modo reseñado, puede ser una cuestión de punto de vista. Cuando consideramos valioso algún aspecto o propiedad predicable de un acto individual estamos considerando que hay una razón para realizarlo, lo que

${ }^{52}$ Raz, 1986, p. 35. Sobre la noción de «razón independiente del contenido», vid. además Hart, 1977, pp. 7 y 27; Raz, 1972, p. 95; Hacker, 1973, pp 166-67; y Sope, 1989, pp. 217-218. 
implica que, presentado como caso del acto genérico o clase de actos de la que son miembros todos los actos individuales con esa misma propiedad, la razón en cuestión es por definición «dependiente del contenido» de aquél. Pero por supuesto es trivialmente verdadero que esa misma razón puede desconectarse o aparecer como «independiente del contenido» del acto cuando éste es presentado bajo otra descripción diferente, es decir, como caso de un acto genérico o clase de actos para pertenecer a la cual no es relevante la concurrencia de aquella propiedad que se reputaba valiosa.

Todo ello sugiere, a mi juicio, que la noción de «razón independiente del contenido» debe ser reinterpretada del siguiente modo. Quien entiende que es valioso (i.e., que hay una razón para) $\emptyset$-siendo $\emptyset$ una acción o un estado de cosas- y constata que dadas ciertas circunstancias contingentes hacer $\emptyset$ ' es una forma de hacer o producir $\emptyset$, ha de concluir que, dadas dichas circunstancias, es valioso (i.e., que hay una razón para) $\emptyset$ '. En un supuesto así, la existencia de ciertas circunstancias contingentes, como razón auxiliar, determina la aplicabilidad a un acto individual -que en ausencia de aquéllas podía ser descrito como $\emptyset^{\prime}$, pero no como $\emptyset_{-}$de la razón operativa que, se den o no dichas circunstancias, se considera que existe para $\emptyset$ (y que, en ausencia de las circunstancias mencionadas, no era específicamente una razón para el acto individual del que estamos hablando).

Obsérvese que cuando concurran las circunstancias contingentes antedichas la calificación de la razón para actuar existente como dependiente o independiente del contenido depende de la descripción que se adopte: descrita la acción como $\emptyset^{\prime}$, la razón para realizarla es independiente de su contenido (puesto que no tendría nada que ver con la «naturaleza o carácter» de $\emptyset^{\prime}$, es decir, con ninguna de las propiedades que han de concurrir en un acto individual para poder describirlo como $\left.\emptyset^{\prime}\right)$; mientras que descrita como $\emptyset$-lo que, dada la existencia de esas circunstancias contingentes, es ahora igualmente posible-, sería dependiente de su contenido. De aquí se deduce, según creo, que cuando sostenemos que hay una razón para realizar una acción cualquiera, ello implica siempre -y no sólo algunas veces, como sugiere la explicación de Hart o Raz- que consideramos valioso algún aspecto o propiedad predicable de ella. Me parece, de todos modos, que la distinción entre razones dependientes e independientes del contenido puede ser conservada si utilizamos el segundo de estos conceptos para referirnos en particular a aquellos casos, merecedores sin duda de ser adecuadamente diferenciados, en que se trate de una propiedad predicable de la acción correspondiente 
sólo en la medida en que existan determinadas circunstancias contingentes.

Si es precisamente la ejecución de ciertos actos ilocucionarios -en el marco de determinadas prácticas sociales- la que determina la aparición de esas circunstancias contingentes, cabe decir que dichos actos han «generado» nuevas razones para actuar en el sentido de que han sido la causa de una modificación del contexto fáctico que ha de ser tomado en cuenta en la deliberación práctica, de manera que la alteración producida atrae hacia cierta acción - la acción prometida, ordenada, etc.- razones preexistentes que hasta entonces no eran específicamente razones para esa acción (si bien, como todo ello depende de circunstancias empíricas -tales como la efectiva alteración de las expectativas y disposiciones de conducta de los agentes implicados-, no hay ninguna conexión conceptual o necesaria entre la ejecución de aquellos actos y la generación de las nuevas razones ${ }^{53}$.

En suma, un agente puede tener dos clases de razones para realizar una acción exigida por una regla social, prometida, ordenada por una autoridad, etc.: razones «dependientes del contenido», que tendría de todos modos si aquella regla social no existiera o si estos actos ilocucionarios no se hubieran realizado; y razones «independientes del contenido», que -eventualmente- tiene porque se han dado esas circunstancias contingentes y que, ceteris paribus, no tendría en caso contrario. Todo agente racional que delibera acerca de si ha de realizar o no una determinada acción ha de construir un balance global en el que integre y sopese todas las razones de una y otra clase que tenga en cada ocasión. Y ese balance global, como es obvio, puede adoptar muy diversas fisonomías: en particular, si hay razones de ambas clases y de distinto signo, nada garantiza a priori que las razones independientes del contenido tengan un peso mayor que las que son dependientes del mismo ni tampoco lo contrario; y cuando sean las primeras las que prevalezcan lo harán justamente por su mayor peso, no porque «excluyan» a las segundas o porque sean una clase especial de razones que por definición estén destinadas a prevalecer siempre sobre estas últimas.

Creo que la toma en consideración de las razones independientes del contenido que eventualmente pueden surgir a partir de

${ }^{53}$ Sobre cómo el ejercicio de poderes normativos o la efectividad de una regla pueden contribuir causalmente a la generación de razones para actuar -en la medida en que alteren el contexto fáctico de la situación-, véase Regan, 1986. Para una explicación pormenorizada del modo en que una promesa o la directiva de una autoridad pueden producir esas alteraciones, me permito remitir nuevamente a Bayón, 1991, apartados 8.4.1 y 8.4.2. 
la realización de ciertos actos ilocucionarios (en el marco de determinadas prácticas sociales) permite dar un sentido aceptable a la idea tan extendida de que cuando se tiene una obligación concurre una cierta «fuerza normativa especial» ausente en aquellas situaciones en las que meramente se debe hacer algo. Esa fuerza normativa especial, de la que según Raz sólo cabe dar cuenta a través de la noción de razón excluyente ${ }^{54}$, provendría simplemente de añadir al balance las razones independientes del contenido eventualmente generadas, adición de la que podría resultar que una acción previamente indiferente se torne debida, que una que ya lo era lo sea ahora con más fuerza o incluso que ahora se deba hacer lo que de otro modo se habría debido omitir. Ahora bien, una cosa es afirmar que la existencia de una regla social, o la formulación de una promesa, o de un mandato de autoridad, etc. pueden generar razones independientes del contenido capaces de cambiar el resultado del balance de razones a favor y en contra y otra, muy distinta, presuponer que generan $-\mathrm{o}$ incluso «son»- razones «para no actuar conforme al balance de razones». Por consiguiente, como han subrayado Gans o Flathman ${ }^{55}$, el prescindir de la noción de razones de segundo orden no nos fuerza a incurrir en el error de afirmar que la deliberación acerca de si realizar o no las acciones exigidas por reglas sociales, prometidas, ordenadas, etc. ha de limitarse a tomar en cuenta los «méritos intrínsecos» de dichas acciones (i.e., las razones dependientes del contenido que de todos modos existirían en ausencia de la regla social, la promesa, el mandato...); y por lo tanto la adición al balance de razones de primer orden de las razones independientes del contenido eventualmente generadas constituiría la explicación más defendible de esa fuerza normativa especial de las obligaciones que Raz atribuye a su presunto carácter de razones excluyentes.

\subsection{Las estrategias indirectas hacia la conformidad: argumento pericial y argumento de la coordinación}

A mi juicio una teoría de las razones para actuar enriquecida con los conceptos de regla indicativa y razón independiente del contenido (ninguno de los cuales, como se ha visto, exige dar entrada a la idea de «razones de segundo orden») es suficiente para dar cuenta de la estructura de los contextos de deliberación práctica en los que Raz considera imprescindible recurrir a la noción de razón excluyente.

\footnotetext{
${ }^{54}$ Cfr. Raz, 1977, p. 223.

${ }^{55}$ Gans, 1981, pp. 200-202; Flathman, 1980, p. 113.
} 
Para confirmar esta conclusión, no obstante, habría que desmontar aún dos argumentos esgrimidos por Raz en defensa de dicho concepto. Estos argumentos -el «argumento pericial» ${ }^{56}$ y el «argumento de la coordinación» ${ }^{57}$ - pretenden demostrar que, por lo menos en dos clases de circunstancias, la racionalidad práctica exige efectivamente dar entrada a la idea de razones excluyentes válidas entendidas como estrategias indirectas hacia la conformidad con las razones subyacentes que excluyen; y que, en rigor, lo que esas estrategias indirectas representan en el razonamiento práctico del agente no puede ser captado sin distorsión a menos que se las conciba precisamente como «razones para no actuar por otras razones», es decir, como razones de segundo orden negativas o excluyentes. En mi opinión, por el contrario, no sólo cabe analizar esas dos situaciones en términos distintos de los que propone Raz, sino que además éstos acaban conduciéndonos a la defensa de pretensiones irracionales.

a) Supongamos que un sujeto A desarrolla su deliberación práctica en condiciones de incertidumbre parcial, bien a causa de su ignorancia acerca de algunos de los hechos relevantes, bien porque es consciente de la existencia de costes de decisión que pueden hacer irracional desarrollarla íntegramente. Supongamos además que A sabe que otro sujeto -B- cuenta con un conocimiento superior al suyo en la esfera correspondiente (es «perito» o «experto» en dicha esfera) y por tanto tiene razones para creer que B está en mejores condiciones que él para determinar qué es en un caso dado lo que resulta del balance de razones que A acepta. En ese supuesto, si B le dice a A que debe hacer $\emptyset$-y A tiene razones para creer que lo que $\mathrm{B}$ le dice que haga es efectivamente lo que de buena fe ha concluido que se debe hacer con arreglo a las razones operativas aceptadas por A y su mejor conocimiento de las razones auxiliares relevantes-, parece que sería racional para A hacer $\emptyset$ aunque él no alcance a ver por qué ésa, y no otra distinta, es la acción óptima en esas circunstancias.

A juicio de Raz esta clase de consideraciones pueden ser aplicables a algunas de las directivas que una autoridad dicte acerca de determinadas materias y ello justificaría -sólo en esos ámbitos o esferas y siempre en las circunstancias- el tratarlas como «razones protegidas». Me parece, sin embargo, que el modo en que un agente racional tomaría en cuenta el juicio

\footnotetext{
${ }^{56}$ Cfr. Raz, 1986, pp. 67-69, Raz, 1989, pp. 1194-1196; PRN, 1990, p. 195.

${ }^{57}$ Cfr. PRN. 1975/1990, p. 64; Raz, 1986, pp. 30, 49-50 y 56; PRN, 1990, p. 195.
} 
de un experto como guía de su acción puede y debe ser explicado sin hacer uso de otro concepto que el de regla indicativa. Alguien que sabe que el juicio de otro acerca de qué es lo que resulta del balance de razones aplicables suele ser más fiable que el suyo propio hará bien en adoptar una regla indicativa a tenor de la cual, cuando tenga la certeza de que no sabe -0 , al menos, no tenga la certeza de que sabe- qué es lo que resulta de ese balance y no disponga de ningún otro criterio mejor al respecto, deberá seguir el juicio de aquél. Pero conviene recordar que el que maneja reglas indicativas no «posterga su propio juicio» ni siquiera cuando las sigue, puesto que las circunstancias en las que encuentra racional seguirlas son precisamente aquéllas en las que no se considera capaz de sostener con seguridad como correcto ningún juicio propio. Y además, como ya sabemos, las reglas indicativas carecen por completo de valor cuando el agente pueda determinar con seguridad qué es lo que resulta en una ocasión del balance de razones -o, por lo menos, cuando sepa que no es lo que la regla indicativa le dice que haga-, lo que es tanto como decir que no puede ser racional «postergar el propio juicio» ante el de aquél cuyo juicio suele ser más fiable cuando se sabe que en una ocasión determinada no lo es, que en esa ocasión se ha equivocado.

En suma: un agente obraría irracionalmente si sólo siguiera el juicio de otro que suele ser más fiable que el suyo propio cuando pudiera estar seguro de que refleja acertadamente el balance de razones subyacentes (lo que equivaldría a manejar la regla indicativa como «absolutamente transparente»); y también si entendiera que debe seguirlo aunque esté seguro de que lo refleja erróneamente (lo que equivaldría a manejarla como «absolutamente opaca»). Y todo ello sugiere, a mi entender, que las directivas del experto o perito han de ser conceptuadas como razones para creer, en determinadas circunstancias, cuáles son con mayor probabilidad las razones para actuar aplicables al caso, no como razones para la acción en sí mismas y menos aún como «razones protegidas».

Raz, evidentemente, discrepa de esa conclusión. Y además conviene insistir en que, tal y como él lo plantea, el desacuerdo no sería meramente verbal, sino que conduciría a conclusiones distintas acerca de qué es realmente lo que exigiría la racionalidad práctica en las circunstancias descritas. Porque, en efecto, a su juicio la relevancia práctica de la directiva del experto no se agota en representar una razón para creer cuál es con la mayor probabilidad la acción requerida por el balance de razones aplicables al caso, sino que constituye una genuina razón para actuar, una razón protegida, lo que implicaría -a diferencia de lo que resultaba de un análisis en términos de reglas indicativas- que la racionalidad 
práctica exige, como estrategia de minimización de errores, postergar el propio juicio acerca de los méritos del caso y actuar de acuerdo con ella siempre, incluso si en un supuesto dado el agente sabe que refleja erróneamente el balance de razones subyacentes ${ }^{58}$.

A mi entender esta última conclusión es irracional y no puede ser aceptada. Y si, como pretende Raz, se desprende del análisis de la situación en términos de razones excluyentes, ello significa que no sólo se puede prescindir de esta noción en el análisis de los razonamientos prácticos, sino que se debe hacerlo. Raz, de todos modos, pretende justificar esa sorprendente tesis alegando que un individuo puede equivocarse no sólo cuando opina acerca de lo que resulta del balance de razones, sino también cuando opina acerca de la cuestión previa de si cuenta o no con elementos de juicio suficientes como para afirmar que está o no seguro de cuál es $-\mathrm{o}$, al menos, de cuál no es- ese resultado. Dicho con otras palabras: cuando el juicio de otro, aun resultando a veces erróneo, es en conjunto más fiable que el propio no tendría sentido adoptar una estrategia consistente en separar los casos en los que uno tiene la certeza de que sabe lo que resulta del balance de razones de aquellos otros en los que no la tiene, de manera que sólo en los segundos se siga el juicio de aquél, porque nada garantiza que en la distinción entre los primeros y los segundos se cometan menos errores que en la determinación de lo que en estos últimos exige el balance de razones; y por consiguiente un agente verdaderamente racional trataría como razones protegidas todas las directivas del experto, incluso cuando crea estar seguro de que son erróneas ${ }^{59}$.

Esta réplica de Raz descansa en la idea de que uno nunca puede distinguir realmente entre lo que sabe y lo que meramente cree, porque cuando decimos que sabemos algo lo único cierto es que creemos que lo sabemos. Pero me parece que este argumento escéptico acerca de la propia certidumbre se vuelve en contra del propio Raz, ya que desde luego él no nos dice que sea racional reemplazar nuestro propio juicio por el de cualquiera, ni por el de alguien que meramente pretenda que su juicio es más fiable, sino por el de aquél cuyo juicio verdaderamente lo sea. Y la pregunta obvia es cómo sabe uno eso. Me parece por tanto que Raz queda atrapado entre los cuernos del siguiente dilema: o bien uno nunca sabe realmente si el juicio de otro es más fiable que el propio, en cuyo caso ha socavado las bases de su propio argumento; o bien, a pesar de que evidentemente un sujeto que se considera seguro de algo puede a pesar de todo equivocarse, entendemos que lo que

\footnotetext{
${ }^{58}$ Raz, 1986, pp. 60-62; PRN, 1990, p. 197.
}

${ }^{59}$ Raz, 1989, p. 1195. 
llamamos certidumbre racional equivale a la existencia de razones suficientes para creer algo, de manera que la misma clase de certeza que uno pueda tener acerca de la mayor fiabilidad en general del juicio de otro puede tenerla también acerca de la comisión de un error por parte de éste en una situación concreta. Y tan pronto como se acepte esto último, queda en mi opinión demostrado que el análisis correcto acerca de la estrategia de un agente verdaderamente racional que en cierto ámbito delibera usualmente en condiciones de incertidumbre parcial (o de existencia de costes de decisión) y que sabe que el juicio de otro sobre el particular es generalmente más fiable que el suyo propio, es el que se desenvuelve en términos de reglas indicativas y no de «razones protegidas».

b) Un problema de coordinación, como es bien sabido, es una situación de interacción estratégica de un tipo especial, en el que todos y cada uno de los agentes implicados entienden que tienen una razón para realizar una cualquiera entre un cierto conjunto de alternativas de conducta a condición de que todos los demás la realicen también. El problema, naturalmente, deriva de que al estar condicionada la elección de cada uno a la elección de los demás se genera una espiral de expectativas mutuas condicionadas que bloquea la elección de todos. Y sólo puede salirse del impasse si alguno de los «equilibrios de coordinación» posibles -i.e., alguna de las combinaciones de estrategias de acción de cada uno tales que si uno cualquiera hiciera algo distinto todos saldrían peor paradosadquiere ante los ojos de todos un carácter sobresaliente, es decir, si cada uno puede contar con la expectativa estable de que es hacia él, y no hacia otro de los posibles, hacia el que se encaminarán los demás ${ }^{60}$. Una solución de este tipo se alcanza frecuentemente de un modo espontáneo, generándose así una convención. Pero también puede conseguirse $-\mathrm{y}$ de una forma comparativamente mucho más eficaz- mediante la emisión de una directiva por parte de una autoridad que ordene ejecutar una acción cuya realización por parte de todos represente uno de los equilibrios de coordinación posibles, de manera que cabría decir entonces que todos los implicados tienen una razón para obedecer dicha directiva, puesto que obedeciéndola queda resuelto el problema en el que se hallan inmersos.

A juicio de Raz, un contexto de ese tipo proporcionaría un segundo argumento en favor del reconocimiento de razones excluyentes válidas: el intento de todos y cada uno de los agentes

${ }^{60}$ Véase al respecto Lewis, 1986, pp. 8-24; y Ullmann-Margalit, 1977, pp. 77-83. 
implicados de actuar con arreglo a su propia estimación de las razones en juego resultaría colectivamente auto-frustrante; y la coordinación sólo se alcanzaría cuando cada individuo postergara su propio juicio al respecto y se limitara a actuar de acuerdo con la directiva de la autoridad, teniendo ello como resultado justamente la conformidad con las razones aplicables al caso (entre las que se contaban las razones de cada uno para modificar la situación de manera que el problema quedara superado). Todo ello demostraría que, en las circunstancias descritas, un agente racional aceptaría esas directivas de la autoridad como «razones protegidas» (es decir, como estrategias indirectas para lograr la conformidad con un conjunto de razones no actuando por esas razones); y, puesto que se habría justificado -por lo menos en ese caso- la existencia de «razones excluyentes válidas», demostraría también que ninguna teoría satisfactoria de las razones para actuar puede prescindir de este último concepto.

Pero me parece que las ideas de «razón excluyente»o de «suspensión o postergación del propio juicio» simplemente no encajan en la estructura de un problema de coordinación. Cuando se habla en esos términos se diría que se está pensando en una pluralidad de individuos cada uno de los cuales tiene un juicio formado acerca de qué hacer, pero que advierten que cuando cada uno sigue el suyo todos están peor, y que por consiguiente reparan en la racionalidad de no actuar de acuerdo con él, sino de acuerdo con la directiva de la autoridad. Pero lo característico de un problema de coordinación es precisamente que los individuos no aciertan a formar un juicio acerca de qué acción realizar: sí tienen un juicio formado acerca de qué resultados se ha de procurar conseguir, pero justamente no saben qué acción realizar para conseguirlos, porque carecen de una expectativa fiable acerca de qué acción es previsible que realicen los demás. Eso es tanto como decir que cada agente tiene razones para realizar aquella acción que previsiblemente realizarán también los demás -y la dificultad de todos consiste en identificarla- y ninguna razón en absoluto para realizar el resto de acciones posibles.

Si la directiva de una autoridad puede proporcionar la solución del problema, habrá de ser entonces porque su emisión consiga modificar las expectativas de los agentes implicados, canalizándolas precisamente hacia la acción prescrita. Si tras la emisión de la directiva cada agente tiene razones para creer que lo que los demás harán es lo que ésta ordena, entonces es sin duda su propio juicio el que le dice que tiene una razón para realizar el contenido de esa directiva. Y en ese caso la resolución del problema depende meramente de la eficacia causal de la directiva en cuando a la 
modificación del contexto fáctico relevante (que no es otro que el entramado de expectativas de los agentes implicados). No hay entonces ninguna razón para actuar que la directiva de la autoridad «excluya», ni razón alguna para que el agente «suspenda» su propio juicio acerca de lo que, en las circunstancias contingentes eventualmente generadas por la directiva, resulta del balance de razones $^{61}$ : lo único que habrá, en su caso, será una modificación -sumamente relevante- de los hechos que, como razones auxiliares, condicionan la conclusión del razonamiento práctico del agente (o, si se quiere, una nueva razón de primer orden -independiente del contenido- que el agente tiene en virtud de las nuevas circunstancias eventualmente producidas por la emisión de la directiva y que, ceteris paribus, no tendría en caso contrario). Y si, por los motivos que sea, el agente tiene razones para creer que la directiva de la autoridad no ha sido causalmente eficaz para generar las expectativas requeridas, entonces sencillamente no tiene ninguna razón para realizar su contenido, ni para limitarse a obedecerla postergando su juicio de que no tiene ninguna razón para hacerlo. La pretensión contraria me parece inevitablemente irracional. Y no creo, por consiguiente, que el argumento de la coordinación demuestre la necesidad de reconocer «razones excluyentes válidas» ${ }^{62}$.

${ }^{61}$ Es lo que, con gran claridad, ha mostrado Green, 1985, pp. 339-340.

${ }^{62}$ Raz ha planteado dos objeciones en contra de esta conclusión. La primera, que para que a un agente le sea posible concluir que tiene una razón para realizar el contenido de la directiva a partir de la previsión de que será cumplida por los demás resultaría indispensable que éstos no hayan desarrollado un razonamiento práctico similar al suyo, puesto que de ese modo se desembocaría en una explicación circular, teniendo que haberse limitado por tanto a aceptar la directiva en cuestión como una razón protegida (cfr. Raz, 1989, pp. 1188-1189). En Bayón, 1991, pp. 670-673 he intentado desarrollar una réplica a esta objeción-basada en la capacidad con que cuenta una autoridad de facto de imponer sanciones y en el conocimiento que todos tienen de esa circunstancia- que por razones de espacio no puede ser reproducida aquí.

En segundo lugar Raz ha alegado que no siempre los individuos tienen una conciencia clara de estar envueltos en un problema de coordinación, que su juicio acerca de si lo están o no es falible, y que si tienen razones para creer que la autoridad es capaz de determinarlo con mayor acierto que ellos mismos, entonces tienen razones para postergar su propio juicio al respecto y aceptar las directivas de la autoridad como razones protegidas (vid. Raz, 1989, p. 1192; PRN, 1990, p. 195). De este modo el argumento de la coordinación queda reconducido al ámbito del argumento pericial: pero, como expuse anteriormente, creo que la idea fracasa porque el argumento pericial sólo puede justificar la adopción de una regla indicativa, no la consideración de las directivas de la autoridad como razones protegidas. 


\subsection{Conclusiones}

Como vimos anteriormente, si el concepto de «razón excluyente» poseyera algún sentido irreductible a un análisis que se desenvolviera meramente en términos de razones de primer orden, habría de ser el de constituir estrategias indirectas hacia la conformidad con las razones excluidas. Pero en ese caso la pertinencia del concepto quedaba pendiente de la demostración de que efectivamente existen razones excluyentes válidas en ese preciso sentido. Ninguno de los argumentos que Raz esgrime para demostrarlo respalda a mi juicio esa conclusión y entiendo por consiguiente que una teoría satisfactoria de las razones para actuar no precisa en modo alguno del concepto de razón excluyente.

Ello obliga a redefinir el papel de las reglas en los razonamientos prácticos, o, si se quiere, la relación existente entre reglas y razones para actuar. A mi entender la respuesta a esa cuestión pasa por distinguir los diferentes sentidos o contextos en los que hablamos de «reglas»: las reglas de la moral crítica o individual que un sujeto acepta, por ejemplo, no serían otra cosa que lo que Raz llama «juicios de deber ordinarios» (es decir, expresarían la existencia de razones -«de primer orden»- que habrían de ser contrapesadas en cada ocasión con el resto de las concurrentes); el sentido de las máximas o reglas de experiencia que comúnmente manejamos en muchos contextos no sería otro que el de constituir reglas indicativas; y el hecho de que exista una regla social o de que una autoridad haya dictado una directiva puede ser determinante, en ciertas condiciones, de las existencia de un conjunto de circunstancias contingentes en las que entra en juego una razón independiente del contenido (que, como ya sabemos, no es sino una razón más de primer orden).

El reto que queda pendiente en la agenda de la teoría del derecho y de la filosofía política, en ese caso, es el de articular análisis satisfactorios del concepto de autoridad legítima y del tipo de razonamiento práctico que está detrás de la aceptación por parte de los órganos aplicadores del sistema de su regla de reconocimiento en los que, a diferencia de lo que propone Raz y también últimamente Hart, se prescinda del concepto de razón excluyente y se haga uso simplemente de las categorías que se acaban de reseñar. Pero esas son cuestiones que, inevitablemente, han de quedar para otra ocasión. 


\section{BIBLIOGRAFÍA}

Atyah, P. S., y Summers, Robert S., 1987: Form and Substance in Anglo-American Law. A Comparative Study in Legal Reasoning, Legal Theory and Legal Institutions. Oxford, Clarendon Press.

Bayón, Juan Carlos, 1991: La normatividad del derecho: deber jurídico y razones para la acción. Madrid, Centro de Estudios Constitucionales.

Clarke, D. S., 1977: «Exclusionary Reasons», Mind 86: 252-255.

Farrell, Martín D., 1986: «Obligaciones jurídicas y razones para actuar: la evolución del pensamiento de Hart», Revista de Ciencias Sociales (Valparaíso) 28: 271-295.

Finnis, John, 1980: Natural Law and Natural Rights. Oxford, Clarendon Press.

Flathman, Richard E., 1980: The Practice of Political Authority. Chicago, University of Chicago Press.

Gans, Chaim, 1981: The Concept of Duty. Oxford University (tesis doctoral inédita).

Green, Leslie, 1985: «Authority and Convention», Philosophical Quarterly 35: 329-346.

Hacker, Peter M. S., 1973: «Sanction Theories of Duty», en A.W.B. Simpson(ed.), Oxford Essays in Jurisprudence (Second Series). Oxford, Clarendon Press; 131-170.

Hare, Richard Mervyn, 1981: Moral Thinking. Its Levels, Method and Point. Oxford, Clarendon Press.

Hart, Herbert L. A., 1977: Obligación jurídica y obligación moral (tr. cast. de J. Esquivel y J. A. Ortiz). México, Cuadernos de Crítica, n. ${ }^{\circ} 3$ [edición original: «Legal and Moral Obligation», en A. I. Melden (ed.), Essays in Moral Philosophy. Seattle, University of Washington Press, 1958; 82-107].

Hart, Herbert L. A., 1982: Essays on Bentham. Siudies in Jurisprudence and Political Theory. Oxford, Clarendon Press.

Jori, Mario, 1980: Il Formalismo Giuridico. Milán, Giuffrè.

Lewis, David K., 1986: Convention. A Philosophical Study. Oxford, Basil Blackwell [1 $1^{\mathrm{a}}$ edición: Cambridge, Mass., Harvard University Press, 1969].

Moore, Michael S., 1989: «Authority, Law and Razian Reasons», Southern California Law Review, 62: 829-896.

Nardin, Terry, 1983: Law, Morality and the Relations of States. Princeton, NJ, Princeton University Press.

Nino, Carlos S., 1984: «Legal Norms and Reasons for Action», Rechtstheorie, 15: 489-502 [ahora, con algunas modificaciones, en Nino, 1985, pp. 125-143].

- 1985: La validez del Derecho. Buenos Aires, Astrea.

- 1986: «El concepto de Derecho de Hart», Revista de Ciencias Sociales (Valparaíso) 28: 33-54.

- 1989a: Ética y Derechos Humanos. Un ensayo de fundamentación ( $2^{\mathrm{a}}$ ed. revisada). Barcelona: Ariel [1ª edición: Buenos Aires, Paidós, 1984]. 
- 1989b: El constructivismo ético. Madrid, Centro de Estudios Constitucionales.

- 1991: «The Epistemological Moral Relevance of Democracy», Ratio Iuris, 4: 36-51.

Perry, Stephen R., 1989: «Second-Order Reasons, Uncertainty and Legal Theory», Southern California Law Review, 62: 913-994.

Raz, Joseph, 1972: «Voluntary Obligations and Normative Powers - II», Proceedings of the Aristotelian Society, Supp. vol. 46: 79-102.

- 1975: Practical Reasons and Norms (1 ${ }^{\mathrm{a}}$, ed.). Londres, Hutchinson.

- 1977: «Promises and Obligations», en P.M.S. y Hacker J. Raz (eds.), Law, Morality and Society. Essays in honour of H. L. A. Hart. Oxford, Clarendon Press; 210-228.

- 1981: «The Purity of the Pure Theory», Revue Internationale de Philosophie, 35: 441-459.

- 1982: La autoridad del derecho. Ensayos sobre derecho y moral (tr. cast. de R. Tamayo), México, UNAM [edición original: The Authority of Law. Essays on Law and Morality. Oxford, Clarendon Press, 1979].

- 1984: «Hart on Moral Rights and Legal Duties», Oxford Journal of Legal Studies, 4: 123-131.

- 1985: «Authority, Law and Morality», The Monist, 68: 295-324.

- 1986: The Morality of Freedom. Oxford, Clarendon Press.

- 1989: «Facing Up: A Reply», Southern California Law Review, 62; 1153-1235.

- 1990: Practical Reason and Norms ( $2^{\mathrm{a}}$ ed., que incluye un nuevo apéndice: «Rethinking Exclusionary Reasons»). Princeton, NJ, Princeton University Press.

Regan, Donald H., 1986, «Law’s Halo», Social Philosophy \& Policy, 4: 15-30.

- 1989: «Authority and Value: Reflections on Raz's Morality of Freedom» Southern California Law Review, 62: 995-1095.

Ruiz Manero, Juan, 1990: Jurisdicción y normas. Dos estudios sobre función jurisdiccional y teoría del Derecho. Madrid, Centro de Estudios Constitucionales.

Soper, Philip, 1989: «Legal Theory and the Claim of Authority», Philosophy \& Public Affairs, 18: 209-237.

Ullmann-Margalit, Edna, 1977: The Emergence of Norms. Oxford, Clarendon Press.

Warnock, G. J., 1971: The Object of Morality. Londres, Methuen. 